\title{
Cancer exosomes and natural killer cells dysfunction: biological roles, clinical significance and implications for immunotherapy
}

\author{
Reza Hosseini ${ }^{1 *}$, Hamzeh Sarvnaz ${ }^{2 \dagger}$, Maedeh Arabpour ${ }^{3+}$, Samira Molaei Ramshe ${ }^{4 \dagger}$, Leila Asef-Kabiri ${ }^{*}$, \\ Hassan Yousefi ${ }^{6}$, Mohammad Esmaeil Akbari ${ }^{5}$ and Nahid Eskandari ${ }^{1}$
}

\begin{abstract}
Tumor-derived exosomes (TDEs) play pivotal roles in several aspects of cancer biology. It is now evident that TDEs also favor tumor growth by negatively affecting anti-tumor immunity. As important sentinels of immune surveillance system, natural killer (NK) cells can recognize malignant cells very early and counteract the tumor development and metastasis without a need for additional activation. Based on this rationale, adoptive transfer of ex vivo expanded NK cells/NK cell lines, such as NK-92 cells, has attracted great attention and is widely studied as a promising immunotherapy for cancer treatment. However, by exploiting various strategies, including secretion of exosomes, cancer cells are able to subvert NK cell responses. This paper reviews the roles of TDEs in cancer-induced NK cells impairments with mechanistic insights. The clinical significance and potential approaches to nullify the effects of TDEs on NK cells in cancer immunotherapy are also discussed.
\end{abstract}

\section{Introduction}

Cancer cells actively release a variety of soluble biomolecules such as cytokines, chemokines, and growth factors to establish tumor microenvironment [1-4]. Over the last decades, extracellular vesicles, especially exosomes, have been known as an important tool of cancer cells in communicating with stromal and distant cells [5-7]. Emerging evidence shows that tumor-derived exosomes (TDEs) contain a variety of molecular components ranging from lipids, membrane-associated proteins, long non-coding RNAs (lncRNAs) and microRNAs (miRNAs) which can alter the behaviour of recipient cells and provide contactindependent routes for the growth of malignant cells $[8$,

\footnotetext{
*Correspondence: reza.hosseini6970@yahoo.com; dr_leili_asef@yahoo.com †Hamzeh Sarvnaz, Maedeh Arabpour and Samira Molaei Ramshe contributed equally to thiswork.

${ }^{1}$ Department of Immunology School of Medicine, Isfahan University of Medical Sciences, Isfahan, Iran

${ }^{5}$ Surgical Oncologist Cancer Research Center, Shahid Beheshti University of Medical Sciences, Tehran, Iran

Full list of author information is available at the end of the article
}

9]. It is increasingly becoming clear that tumor exosomes are involved in several processes of tumor formation and invasion, including angiogenesis, proliferation and growth, metastasis and immune escape [9-11].

Of particular note, several lines of evidence support that TDEs are the key immunomodulatory players of tumor microenvironment [12]. In this regard, these tumor-derived particles were shown to manipulate both innate and adaptive immune responses in favor of tumor progression $[12,13]$. Numerous studies have shown that exosomes derived from tumor cells demolish anti-tumor immunity by impairing the function of DCs, NK cells and $\mathrm{T}$ cells $[14,15]$. Among them, NK cells are considered as initial responders to malignant cellular transformation. Despite the CD8 + CTL responses, NK cells do not require prior antigen exposure to recognize tumor cells, marks them as the early line of defense against cancer cells [16]. Indeed, NK cells express a repertoire of inhibitory (KIR, CD94-NKG2A, etc.) and activating receptors (e.g. NKG2D, NKp30, NKp44, and NKp46) which defines original author(s) and the source, provide a link to the Creative Commons licence, and indicate if changes were made. The images or other third party material in this article are included in the article's Creative Commons licence, unless indicated otherwise in a credit line to the material. If material is not included in the article's Creative Commons licence and your intended use is not permitted by statutory regulation or exceeds the permitted use, you will need to obtain permission directly from the copyright holder. To view a copy of this licence, visit http://creativecommons.org/licenses/by/4.0/. The Creative Commons Public Domain Dedication waiver (http://creativeco mmons.org/publicdomain/zero/1.0/) applies to the data made available in this article, unless otherwise stated in a credit line to the data. 
their fate and enable them to recognize their ligands on transformed cells [17]. Although lower expression of the major histocompatibility complex I (MHCI) molecules and ligands for activating receptors on tumor cells is assumed to stimulate NK cells activity, but tumor cells could dampen NK cells function via different mechanisms [16, 18]. Recent data have pointed out that tumor exosomes play critical roles in NK cells dysfunction [1921]. It is believed that TDEs can be taken up by NK cells or induce downstream signals through receptor-ligand interactions, downmodulating their anti-tumor activity $[13,22]$. There is also a large body of evidence indicating that tumor exosomes harbor a plethora of surface ligands and biomolecules that can interfere with the recruitment, cytokine production, molecular expression and cytolytic activity of NK cells [23]. Notably, TDEs are also assumed to counteract the beneficial effects of NK-based immunotherapy $[14,23]$. Although some reports have shown an immunostimulating role of cancer-derived extracellular vesicles [24-31], but here we will mainly focus on their inhibitory effects and review the roles of TDEs in NKcells dysfunction with mechanistic insights and summarize the clinical significance and therapeutic approaches to counter exosome-dependent tumor-induced NK cells impairment in treating cancers.

\section{Uptake/Interactions of TDEs with NK cells}

Tumor-derived exosomes (TDEs) can be taken up by various cells, preferentially immune cells, through plasma membrane fusion, endocytosis, phagocytosis, micro pinocytosis, and lipid raft-mediated internalization [14, 32]. The uptake/interaction of tumor exosomes with immune cells is believed to participate in immune suppression and tumor escape [32, 33]. There are multiple findings indicating that tumor exosomes can deliver their cargo into NK cells via fusion with the cell membrane, hindering their anti-tumor function [19]. Studies have shown that exosomes from pancreatic cancer cells (L3.6pl) and murine mammary carcinoma cells (TS/A) are taken up by NK cells and stably present in cytoplasm which is accounted for their decreased cytotoxic activity [34, 35]. Oral cancer-derived exosomes and those obtained from leukemic cell line (Jurkat cells) were also demonstrated to be internalized by NK and NK-92MI cells $[22,36]$. In vivo experiments also showed that the inject exosomes derived from gastric cancer cell lines (MKN-45, MKN-28, and SGC-7901) are mainly taken up by NK cells and macrophages, contributing to the lung metastasis of gastric cancer cells [13]. In a study on lung cancer, microvesicles (MVs) derived from normoxic and hypoxic IGR-Heu and K562 tumor cells are also internalized by NK cells at the same levels [37]. However, contrary to the above-mentioned studies, NK cells exhibited poor capability in uptake of exosomes-derived from breast cancer (EO771) cells, lymphoma-derived exosomes and those isolated from MCL (mantle cell lymphoma) patients [32, 38, 39]. This is in agreement with the observations that the efficiency of uptake by NK cells differ markedly for the exosomes derived from different tumors (including hepatoblastoma (HepG2 cells), cervix cancer (Hela cells), breast cancer (MCF-7 cells), myeloid leukemia cells (K562), and T leukemia cells (Jurkat)) [40]. Indeed, there might be some exosomes-associated molecules determining their cellular uptake. For example, blocking of phosphatidylserine (PS) was found to inhibit the uptake of ovarian cancer-derived exosomes by NK cells, suggesting a PS-dependent uptake mechanism [41]. Apart from their uptake, several lines of evidence also show that TDEs may affect immune cells ( $\mathrm{T}$ cells, macrophages, dendritic cells, Regulatory $\mathrm{T}$ cells) by triggering signals via ligand-receptor interactions [42-44]. In accordance, it was demonstrated that TDEs reprogram NK-92 cells to block their anti-leukemia cytotoxic functions, mainly through signaling via surface receptors [23]. The corresponding results showed that the interaction of exosomal ligands (including but not limited to TGFb) with their cognate receptors on NK cells can induce multiple downstream inhibitory signaling pathways, suppressing their anti-tumor activity [23] (Fig. 1a).

\section{TDEs regulate recruitment and migration of NK cells}

Shreds of evidence indicate that TDEs actively affect recruitment and migration of cancer and immune cells to establish tumor microenvironment and metastatic niche $[42,45,46]$. A previous study showed that tumor exosomes mediate the migration of MDSCs and contribute to the metastasis of murine breast cancer cells (4T1 cells) to the lung in a CCL2-dependent manner [47]. Others have shown that exosomes-derived from B16F10 (mouse melanoma; epithelial-like cells), CT26.WT (mouse colon carcinoma; fibroblasts), and LTPA (mouse pancreatic adenocarcinoma; epithelial cells) have high levels of CX3CR1 [48]. It was revealed that this exosomal CX3CR1 could bind to its soluble ligand (CX3CL1), suggesting that might play a role in intercellular crosstalk [48]. Exosomal chemokine from heat-stressed tumor cells were also shown to affect the mobility of DCs [49]. Besides, horizontal transfer of exosomal chemokine receptors, such as CXCR4, has been shown to enhance the migration of hepatocellular carcinoma cells [50]. Similar to these findings, a recent study demonstrated that exosomes isolated from AML patients could significantly reduce the migration of NK-92 cells toward tumor cells [23]. Further proteome profiling revealed that AML exosomes are highly enriched in CXCL4, CXCL7, and CCL5 (RANTES) compared to exosomes obtained from 


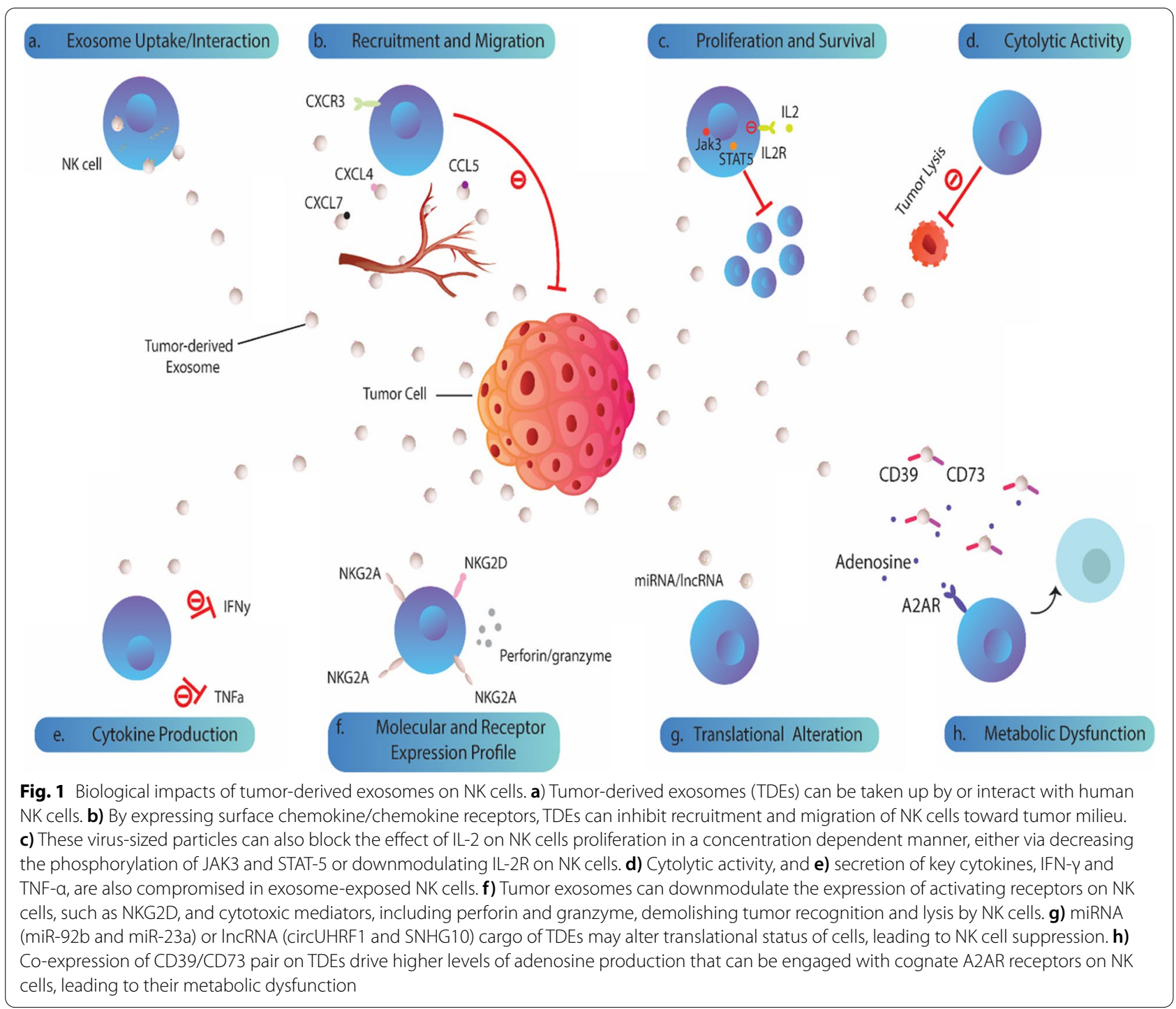

healthy donors [23]. Notably, the co-incubation with AML exosomes reduced CXCR3 expression on NK-92 cells surface, suggesting that down-regulation of CXCR3 levels by AML exosomes might be ligand-mediated and responsible for the decreased migration of NK-92 cells into the tumor site [23] (Fig. 1b). Such findings indicate that TDEs could impact several important biological processes, including chemotaxis and recruitment of immune cells (such as NK cells) into the tumor site.

\section{TDEs affect proliferation and survival of NK Cells}

The literature supports that tumor secretome, including TDEs; dominantly favor tumor progression by downregulating proliferation and survival of immune cells [5153]. In a pioneer research, exploring the effects of tumor exosomes on the proliferation and survival of NK cells, it was revealed that pretreatment with murine mammary carcinoma (TS/A cells) exosomes reduces the number and percentage of NK cells in vitro [35]. Alongside, the injection of TS/A exosomes into Balb/C mice was also found to significantly reduce NK cells number and percentage in the lung, but not in the liver and lymph nodes. With attention to the details, the total number of splenocytes and NK cells was observed to be increased following the treatment of mice with tumor exosomes; however, the percentage of NK cells in the spleen was decreased [35]. These findings implied that TS/A-exosomes may inhibit NK cells proliferation in vivo, leading to the tumor immune-escape. To further elucidate this observation, researchers have examined the effect of tumor exosomes on IL-2-dependent NK cell proliferation pathway [35]. Subsequent results showed that not only TS/A 
exosomes but also exosomes from MDA231 (human breast cancer), A2058 (human melanoma), and the 4 T.1 (murine breast cancer) cell lines could significantly block the proliferation of NK cells induced by IL-2 [35]. More detailed investigation of signaling pathways downstream of IL-2R revealed that the activity of $\mathrm{p} 42 / \mathrm{p} 44$ and of Akt, a substrate of PI3K, in NK cells did not change following the treatment with TDEs. However, exosomes were able to inhibit Jak3 expression, as a reduction in the levels of phosphorylated Stat5 was observed [35]. Of particular note, the resultant decrease in Stat5 phosphorylation was dependent on the concentration of TDEs (Fig. 1c). Similarly, a dose-dependent reduction in cyclin D3 and phosphorylated levels of its substrate $\mathrm{Rb}$ was also seen in NK cells treated with tumor exosomes. However, it was found that the reduced cytotoxic activity of NK cells treated with TS/A exosomes is not due to apoptosis, and co-incubation with TS/A exosomes did not change the viability of NK cells [35]. Exosomes from human tumor cells (mesothelioma cell line) was also found to selectively impair peripheral blood lymphocytes response to IL-2 [54]. However, it was noted that these exosomes selectively downmodulate expression of the high-affinity IL-2 receptor on cytotoxic effector cells including NK cells, thereby inhibit their IL-2 driven proliferation [54]. Other research have also shown a decreased proliferation of NK-92 incubated with AML exosomes [23] and a decreased frequency of CD8 $+\mathrm{T}$ and NK cells following the injection of gastric cancer-derived exosomes; however these anti-proliferative effects have not been attributed to the induction of apoptosis [13, 23]. Treating with multiple myeloma-derived exosomes (MM-EXs) also affected neither apoptosis nor proliferation of NK cells [55] (Fig. 1c).

\section{TDEs alter cytolytic activity of NK cells}

In spite of inhibiting the early stage of tumor formation, NK cells also are able to eradicate solid tumors through cytotoxic functions $[56,57]$. However, studies have confirmed that tumor cells robustly inhibit tumoricidal activity of NK cells. Recent data show that, in addition to reducing NK cells count, tumor exosomes are a candidate that reduces cytolytic activity of NK cells in tumor context [23]. It has been demonstrated that the treatment of NK-92 cells with AML exosomes significantly inhibits their cytotoxicity against K562 cells [23]. Likewise, NK cells pre-treated with pancreatic cancer-derived EVs exhibited decreased cytotoxicity against pancreatic CSCs [34]. Such a mechanism is assumed may help CSCs to avoid of elimination by NK cells, potentially leading to tumor recurrence $[58,59]$. It is interesting to note that saliva exosomes derived from pancreatic cancer cells were also shown to decrease cytolytic potential of NK cells both in vitro and in vivo [60]. Others investigating the effect of oral cancer-derived exosomes on the cytotoxicity of NK cells have reported that the oral cancer cell-killing effect of NK cells could be increased following the co-incubation of NK cells with the OCEXs in a short time, however by increasing the incubation time, the cytotoxicity of NK cells was dramatically decreased [22]. These findings imply that although TDEs may stimulate NK cells cytotoxicity at short time, but long time exposure to TDEs can inhibit their cytolytic function, resulting in immune escape and cancer progression. Similarly, it was also shown that NK cells cytotoxicity is impaired in mice treated intra-peritoneally with the exosomes either produced by murine mammary TS/A or 4 T.1 tumor cell lines [35]. Furthermore, although similar uptake patterns have been observed for normoxic and hypoxic tumorderived MVs, but NK cells co-cultured with normoxic or hypoxic MVs displayed different levels of cytotoxicity [37]. Strikingly, the NK cells treated with hypoxic tumorderived MVs exhibited significantly lower cytotoxicity toward IGR-Heu or K562 tumor cells than normoxic MVs-treated NK cells [37] (Fig. 1d).

Consistent with the previous studies, treatment with multiple myeloma exosomes was also shown to significantly reduce the cytotoxic function of NK cells against K562 cells [55]. Anti-tumor activity of CD3 - CD56 + NK cells against $\mathrm{K} 562$ targets was also significantly inhibited by exosomes isolated from plasma of HNC patients; while no suppression was observed with exosomes isolated either from healthy donors or those patients with no evident disease [23]. Others have revealed that exosomes of AML and head and neck cancer (HNC) patients as well as glioblastoma-derived exosomes (GBex) markedly suppress human NK cells function [61-63]. In a well-designed study, researcher have examined whether exosomes derived from clear cell renal cell carcinoma (ccRCC) cells are involved in the process of deactivation of NK cells [64]. For this purpose, purified human NK cells were cultured in a transwell coculture system with primary cells derived from non-tumor tissue (NT), margin region $(\mathrm{M})$ and tumor $(\mathrm{T})$ tissues separately. It was found that only exosomes from primary ccRCC cells $(\mathrm{T})$ induce NK cell dysfunction. More importantly, the findings revealed that exosomes isolated from ccRCC cells in advanced stage (III/IV) had more suppressive effects on NK cells than those in early stage (I/II) [64] (Fig. 1d).

\section{TDEs modulate cytokine production by NK cells}

Since TDEs exert large effects on immune cells, thus it would be expected that exposure to tumor exosomes can also alter cytokine production by NK cells $[13,42,65]$. Tumor necrosis factor- $\alpha$ (TNF- $\alpha$ ) and interferon- $\gamma$ (IFN$\gamma)$ are two main cytokines produced by activated NK 
cells, orchestrating anti-tumor immune responses [66, 67]. Exosomes from cholangiocarcinoma were found to significantly inhibit NK cells secretion of TNF- $\alpha$, reducing their anti-tumor function [68]. Similarly, NK cells coincubated with pancreatic cancer (L3.6pl)-derived EVs had a significant decrease in TNF-1, and IFN- $\gamma$ production [34]. Treatment with TS/A (murine mammary carcinoma cells) exosomes were also shown to significantly inhibit the release of IFN- $\gamma$ in IL-2-stimulated NK cells, suggesting that tumor exosomes could impair production of cytokines by activated NK cells [35]. Reduced IFNY expression has also been observed in NK cells pre-treated with normoxic or hypoxic tumor-derived MVs [37]. Notably, hypoxic tumor MVs exhibited more significant effects on the decrease of IFNY production by NK cells compared to normoxic MVs, and decreased cytotoxicity of exosome-treated NK-92/NKD cells was found to be directly correlated with the reduced expression of IFNY by these cells [37] (Fig. 1e).

\section{TDEs alter receptor and molecular expression patterns of NK cells}

The function of NK cells is known to be tightly regulated by activating and inhibitory receptors [69]. NKG2D and NKp30, NKp44, NKp46 are important activating receptors on NK cells and their expression levels determine the antitumor capacity of NK cells [70-72]. On the other side, the expression of NKG2A, one of the most important inhibitory receptors of NK cells, is negatively associated with their antitumor activity [73, 74]. Also, the cytolytic function of activated NK cells is largely depended on the release of granzyme B and perforin that mediate contact-dependent NK cells function $[16,75]$. As a fact, tumor cells use different mechanisms to manipulate the expression of these molecules on NK cells, shifting the balance toward tumor progression [16]. Because TDEs mirror the content of parental cells, thus it is highly likely that these particles also play a part in altered receptor and molecular expression, underpinning tumor-associated NK cells dysfunction [76]. Recently, investigating the effects of oral cancer-derived exosomes (OCEXs) on NKG2D, NKp30, NKp44, NKp46 and NKG2A expression by NK cells, researchers observed that OCEXs significantly upregulate the expression of activating receptors (NKG2D, NKp30, NKp44 and NKp46) on the NK92MI cells for $24 \mathrm{~h}$ following treatment, whereas the expression of NKG2A was remarkably decreased at the same timeline [22]. Notably, further experiments revealed a gradual decrease in the expression of activating receptors on NK cells over the time for 7 days, while, no significant changes were observed for NKG2A expression in this time [22]. Since tumors constantly release exosomes into surrounding microenvironment as well as into the circulation, thus NK cells are more likely to be continually exposed to tumor exosomes, leading to an ultimate loss of cytotoxic function in NK cells. Others have also shown that murine mammary carcinoma (TS/A cells) exosomes selectively modulate the expression of cytolytic effector molecules in NK cells [35]. It was found that co-culture of the cytokine activated-NK cells with tumor exosomes dramatically reduce perforin in a dosedependent manner, while the expression of granzyme $\mathrm{B}$ did not change [35]. Interestingly, pretreatment of NK cells with murine breast cancer exosomes was observed to not affect the expression of perforin mRNA, indicating that tumor exosomes might affect perforin expression at protein levels [35]. Exosomes derived from multiple myeloma and pancreatic cancer cells (L3.6pl cells) were also demonstrated to downregulate the expression of NKG2D on natural killer (NK) [34, 55]. Furthermore, saliva exosomes from pancreatic ductal carcinoma (PADC) bearing mice were also demonstrated to trigger surface NKG2D down-modulation and significantly decrease granzyme B and perforin expression [60]. The same results were also reported by others. It has been shown that CD34+exosomes from AML patients' plasma (circulating blast-derived exosomes) significantly inhibited NKG2D expression on NK cells and reduced NKp46 [77]. Mesothelioma-derived exosomes co-cultured with peripheral blood lymphocytes (PBLs) were also shown to reduce both the proportion of NKG2D-positive cells as well as the surface expression of NKG2D [78]. This phenotypic alteration was specific, as it was noted that tumor-exosome treatment did not alter expression of CD3, CD4, CD8, CD56, or CD16 [78]. In particular, the expression level of CD94, a molecule that is also expressed in association with NKG2 receptors on a subset of NK cells and CD8 T cells, was found unchanged following tumor exosome treatment [78]. To determine whether TDEs-mediated NKG2D down-modulation can affect NK cell activation, researchers have examined the expression of the activation marker CD69. As a result, treatment with tumor exosomes was observed does not alter CD69 expression [78]. Similarly, no changes were observed in the constitutive perforin or granzyme B expression. These findings implied that tumor exosomes mediate these effects directly, and do not require the activity of CD4 T cells, or dendritic cells [78]. Although surface NKG2D was decreased following exosome treatment, however the total cellular NKG2D was largely stable, confirming that tumor exosomes induce internalization of NKG2D from the surface [78]. This provides the evidence that tumor exosomes can selectively trigger a decrease in cell surface NKG2D, without concomitant cellular activation. Consistently, NK and CD8+ T cells isolated from patients with castration-resistant PC 
(CRPC) exhibit a significant decrease in surface NKG2D expression compared to healthy individuals [79]. Coincubation of exosomes isolated from serum or plasma of CRPC patients with lymphocytes from healthy donors also triggered the downregulation of NKG2D expression. To further clarify these observations, researchers have examined the expression of NKG2D by PBMCs after in vitro incubation with prostate cancer 22Rv1 cellsderived exosomes [79]. Significantly reduced cell-surface NKG2D expression was observed after $24 \mathrm{~h}$ in CD8 $+\mathrm{T}$ cells and NK cells treated with 22Rv1 exosomes [79]. This downregulation was evident both as a decrease in the proportion of NKG2D-positive cells and a reduction in the mean fluorescence intensity (MFI) compared to untreated PBMCs. It was concluded that this reduced NKG2D expression induced by 22Rv1 exosomes was NKG2D receptor-specific, since exosome treatment did not change the expression of CD3, CD8, CD56, CD16 or the activation marker CD69 [79]. Further experiments were also done to test whether the NKG2D receptor was internalized or merely masked on the cell surface by exosomes. The findings showed that the cell-surface downregulation of NKG2D by 22Rv1 exosomes was dose-dependent and mediated by the receptor internalization. More importantly, 22Rv1-derived exosomes were able to downregulate the NKG2D-dependent killing ability of PBMCs from healthy donors [79]. Together, these results support the notion that TDEs may affect NK cells function through downregulating NKG2D, granzyme and perforin expression (Fig. 1f).

\section{What molecules underlie TDEs-mediated NK cell dysfunction?}

Tumor exosomes can actively induce immunosuppression through several mechanisms and cellular or subcellular pathways $[12,80]$. A variety of immunoinhibitory proteins on their surface, as well as lipid and RNA (miRNA, lncRNA, etc.) content of TDEs can influence immune cells, including NK cells [12]. Here, we summarized the previously evidenced biomolecules that are involved in TDEs-mediated NK cells dysfunction (Table 1).

\section{Exosomal ligands for NKG2D (MICA/B and ULBP1-6)}

The continuous exposure of NK cells to ligands expressed on the surface of tumor cells have been demonstrated to result in NK cells abnormalities [92, 93]. As mentioned earlier, the absence or downregulated levels of NKG2D are a common feature of functionally suppressed NK cells that might be induced by tumors or soluble factors derived from tumor/surrounding cells [94, 95]. Studies show that the MHC class I-related chain (MIC) A and MICB ligands for the activating receptor NKG2D can be shed from tumor cells and their presence in patients' plasma is closely associated with the compromised NK cell responses and disease progression [96, 97]. Because the presence of MICA and MICB on tumor exosomes has been validated, thus it is likely that exosomal MICA/B might be able to alter NKG2D expression similar to their soluble counterparts [98-100]. Concerning this, AML exosomes were revealed to be rich in membrane-associated MICA/MICB that are assumed to be responsible for NKG2D downregulation and concomitant reduction of NK-cell cytotoxicity [23]. Others have also reported shedding of the most frequently expressed MICA allele in human populations (MICA*008) into exosomes [82]. Based on the findings, NK cells treated with MICA*008 containing exosomes derived from human cervical cancer Hela cells had significantly downregulated expression of NKG2D with a marked reduction in cytotoxic activity. Comparing the effect of MICA*008 (released in exosomes) or MICA*019 (soluble) on the expression of NKG2D on primary human NK cells, it was found that culture supernatants containing either MICA*019 or MICA*008 can significantly decrease cell surface NKG2D expression, whereas MICA*008 containing supernatant (exosomal form) induced more downregulation of NKG2D [82]. Likewise, examining whether the downmodulation of NKG2D was dependent on exosome phenotype, a previous study found that exosomes isolated from NKG2D ligand-positive tumor cells, including mesothelioma cell line, prostate cell lines (PC3 or DU145), EBV-B lymphoblastoid cells (IB4), or exosomes purified from a mesothelioma patient's pleural fluid (PF) were capable of driving down the expression of NKG2D in NK cells [78]. In contrast, exosomes from PBMCs or fibroblasts had no effect on NKG2D expression. These findings showed that the decrease in NK cell NKG2D is exosome phenotype dependent, and occurs with tumor but not with non-tumor exosomes [78]. To determine whether exosomal NKG2D-ligand expression is involved in this down-regulation, similar assays were performed using mesothelioma cell line-derived exosomes, that strongly express surface MICA, in the presence of neutralizing MICA-specific Ab or isotype-matched control $\mathrm{Ab}$ [78]. It was observed that the exosome-mediated down-modulation of NKG2D was inhibited by antiMICA, but not isotype- control $\mathrm{Ab}$, confirming that reduced NKG2D surface expression occurs with tumor but not with non-tumor exosomes, and is at least in part due to exosomal MICA expression [78]. In a similar setting of experiments, pre-incubating with anti-ULBP and anti-MIC mAbs significantly inhibited the downregulation of NKG2D expression induced by exosomes from prostate cancer cells (22Rv1 cells) [79]. However, on the other hand, pre-treatment of 22Rv1 exosomes 
Table 1 The bimolecular cargo of TDEs and their inhibitory effects on NK cells

Exosomal Cell of Origin Mechanism of Action

Ligands for NKG2D (MICA/B and ULBP1-6)

AML

AML

Metastatic melanoma

Saliva exosomes (pancreatic ductal carcinoma (PADC)

HELA, HepG2 and MelJuso

Mesothelioma cell line, prostate cell lines (PC3 or DU145), and EBV-B lymphoblastoid cells (IB4)

Jurkat and Raji cell lines

22Rv1 ( human prostate carcinoma epithelial cell line)

Epithelial ovarian cancer (EOC)

TGF-b

AML

AML

ALL

Pancreatic cancer

Oral cancer

Non-small cell lung cancer (NSCLC)

Clear cell renal cell carcinoma (ccRCC)

\section{Adenosine and Glucose Metabolism}

AML

Glioblastoma

Pancreatic cancer cells (L3.6pl)

Fas-L, Survivin, B7-H3 and PD-L1

Lymphoma

Glioblastoma cells

Melanoma

RNAs

Hepatoma

NSCLC

Hepatocellular carcinoma (HCC)

Colorectal cancer
Downregulate NKG2D expression and reduce NK-cell cytotoxicity

CD34 + exosomes downregulate NK cells activity through decreasing NKG2D [77] levels

Downregulating NKG2D expression on NK cells

[81]

Decreases NK cell activation level and triggers downregulation of surface NKG2D

Particle-associated MICA (MICA*008) downregulates NKG2D expression

Downregulation of surface MICA expression on NK cells

Exosomal ligands for MICA/B and ULBP1 and 2 downregulate the expression of MICA/B

Exosomal MICA/B and ULBPs downregulate NKG2D expression

Induce NKG2D downregulation, but do not affect DNAM-1-PVR/nectin-2 pathway

Decreases NKG2D expression through SMAD2/3 pathways in NK-92 cells, but do not affect DAP-10 expression

Down-regulation of NKG2D receptors and suppression of NK cells activity through the phosphorylation of SMAD1/5/8

Induction of TGF-b signaling by upregulating MDS1 and EVI1 expression

Delivering TGF-b to NK cells and activating the phosphorylation of Smad2/3 signaling pathway

Decreasing the expression of NKp30 and NKG2D on NK cells

Hypoxic MV had higher TGF-b levels and decreased surface NKG2D expression

Abrogating cytotoxic function of NK cells through the activation of the TGF-b/SMAD signaling pathway

Induces adenosine production in TME by expressing CD39/CD73 pair and impair NK cells function via A2AR

Carrying CD39 and CD73 and mediate NK cells dysfunction

Reduces the expression of CD71 (transferrin receptor), CD98 (large neutral amino acid transporter) on NK cells

Exosomal Fas-L and Survivin induces NK cell impairment by reducing the expression of perforin, granzyme B, TNF-a, IFN- $\gamma$ and NKG2D

$[86]$

B7-H3 carrying exosomes impair NK-mediated tumor lysis

PD-L1 + exosomes induce NK cells dysfunction through PD-L1/PD1 axis

miR-92b containing exosomes alter CD69 expression on NK cells and impair their activity

Downregulating CD107a through miR-23a

-Ring finger domain 1 RNA (circUHRF1) containing exosomes decrease proportion and infiltration of NK cell

-Exosomal circUHRF1 enhancing TIM-3 expression via degradation of miR$449 c-5 p$

IncRNA SNHG10 induces inhibin subunit beta C (INHBC), which is involved in the TGF- $\beta$ signaling pathway 
with an anti-CD63 mAb, a known exosomal protein, did not significantly affect the expression of NKG2D [79]. The immunosuppressive ability of epithelial ovarian cancer (EOC) exosomes on two cytotoxic pathways of importance for anticancer immunity, the NKG2D receptor-ligand pathway and the DNAM-1-PVR/nectin-2 pathway, has also been investigated [84]. It was shown that exosomes isolated from EOC tumor explant and EOC cell-line culture supernatants, and ascitic fluid from EOC patients differentially and constitutively express NKG2D ligands from both MICA/B and ULBP families on their surface, while DNAM-1 ligands are more seldom expressed and not associated with the exosomal membrane surface [84]. The NKG2D ligand-bearing EOC exosomes was found to significantly downregulate the NKG2D receptor expression on peripheral blood mononuclear cells (PBMC) while the DNAM-1 receptor was remained unaffected [84]. Of note, the downregulation of NKG2D expression was observed to be associated with lesser NKG2D receptor-ligand-mediated degranulation and cytotoxicity of NK cells in vitro against OVCAR-3 and $\mathrm{K} 562$ cells. It was inferred that the EOC exosomes act as a decoy, thereby impairing the NKG2D-mediated activity of NK cells [84] (Fig. 2). Furthermore, investigating whether TDEs contribute to the immune evasion from NK surveillance as a cause of high relapse and fatal outcome of many blood malignancies [83, 101], researchers have employed Jurkat and Raji cell lines, as a model for studies of the NKG2D receptor-ligand system in T-and B cell leukemia/lymphoma [83]. Preliminary findings showed that Jurkat and Raji cells constitutively express mRNA and protein for the stress-inducible NKG2D ligands MICA/B and ULBP1 and 2, and actively release them by exosomes. Further results showed that the NKG2D ligand-bearing exosomes derived from Jurkat and Raji cell lines could act as a decoy and downregulate

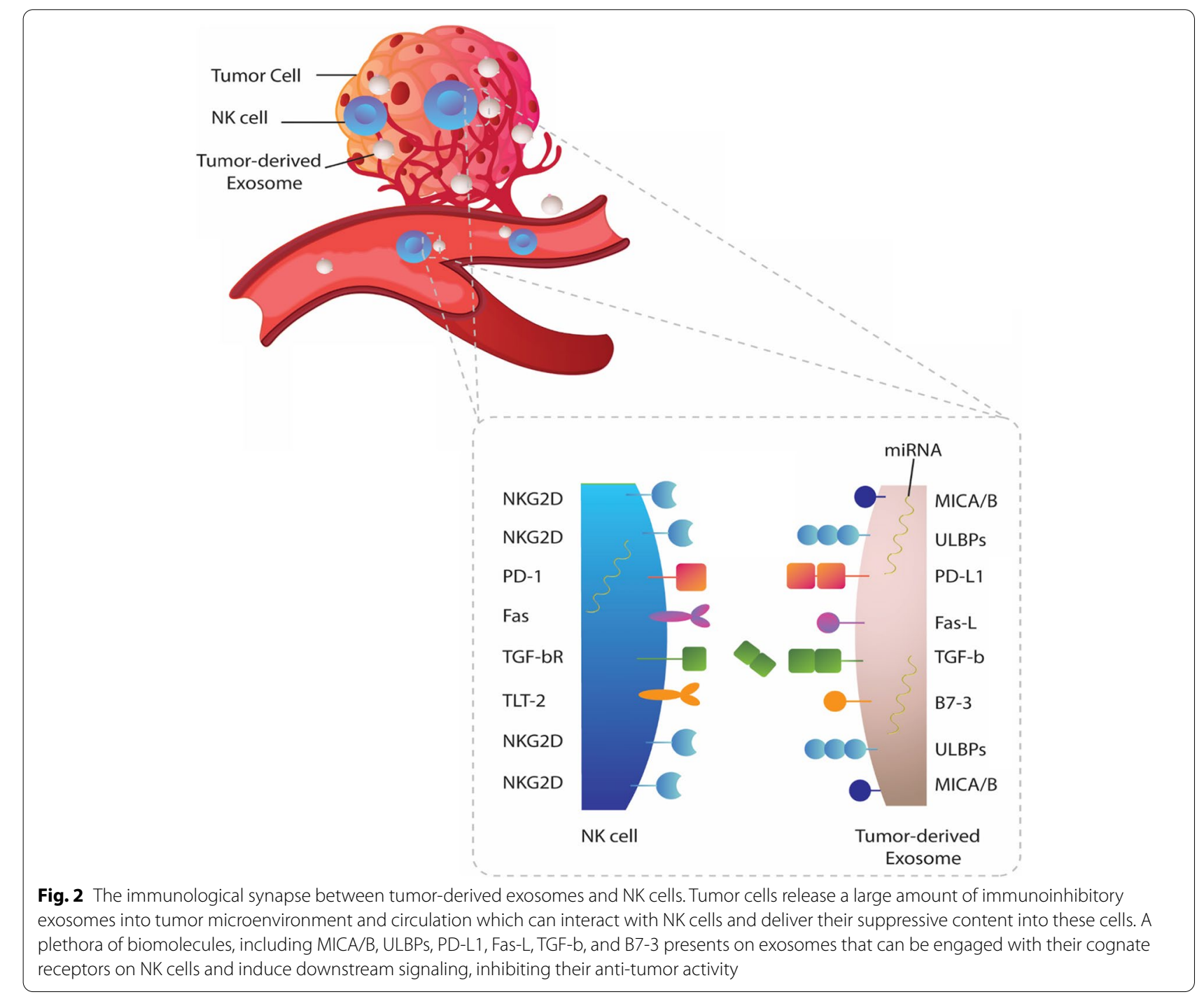


the NKG2D receptor-mediated cytotoxicity of NK cells in vitro [83]. Emphasizing the role of exosomal ULBPs, others have also revealed that tumor cells release exosomal ULBP3 which is more potent for NKG2D downregulation compared to soluble ULBP2, limiting cytotoxic activity of NK cells [102]. These results might partly explain the clinically observed NK-cell dysfunction in patients suffering from leukemia/lymphoma, and suggest that exosomal ligands for NKG2D play crucial roles in tumor-associated NK cells abnormalities. As a matter of importance, thermal and oxidative stress was found to enhance the secretion of NKG2DL-bearing exosomes that aggravated the impairment of the cytotoxic response by NK cells [83]. Therefore, the adverse effect of thermal and oxidative stress, enhancing the release of immunosuppressive exosomes, should be considered when cytostatic and hyperthermal anti-cancer therapies are designed [83].

In spite of carrying exosomal NKG2D ligands on their surface, it is strongly speculated that cancer-derived exosomes may also influence cellular function through a variety of biological mechanisms to the benefit of the tumors that produce them [103, 104]. For example, due to its expression on exosomes, previous studies inferred that exosomal MICA derived from metastatic melanoma cell line (Ma- Mel-86c) is responsible for the NKG2D downregulation $[81,105,106]$. On the contrary, a recent study on exosomes from melanoma patients revealed that although melanoma exosomes could induce NKG2D downregulation on NK cells, but this effect is unrelated to exosomal MICA/B [88]. These results support that exosomal NKG2D ligands are, in part, responsible for downregulating the expression of NKG2D receptor, and there might be other exosomal biomolecules rather than MICA/B that are involved in this phenomenon (Fig. 2).

\section{Exosomal TGF-b}

Transforming growth factor-beta (TGF-b), a cytokine of the bone morphogenetic protein (BMP)-activin family, is well-known to participate in a wide range of processes involving regulation of immune responses [107-109]. It is especially acknowledged for its inhibitory effects on immune cells, including NK cells [110, 111]. Strong evidence show that TGF-b reduces the surface expression of crucial activating receptors (NKp30 and NKG2D) on NK cells and elevated levels of this cytokine is associated with impaired activity of NK cells in cancer patients [112-115]. Most recent studies indicate that tumor exosomes also carry high levels of membrane-associated TGF-b that may induce immunosuppressive effects similar to its soluble counterpart. There are now multiple reports showing that exosomes/MVs isolated from AML and clear cell renal cell carcinoma (ccRCC) patients or mesothelioma cells contain significant levels of mature TGF-b $[23,78,85,116]$. Nevertheless, a pro-peptide isoform of TGF-b comprised of the LAP covalently bound to mature TGF-b $(\sim 50 \mathrm{kDa})$ has also been reported on AML exosomes (99), and this latent form of TGF-b was shown to be dissociated following treatment with urea, further increases soluble TGF-b levels [85]. Of particular note, there is a broad consensus that TGF-b containing tumor exosomes are capable of driving down NKG2D levels on NK cells comparable to that seen for soluble TGF-b, whereas neutralizing antibodies against TGF-b can restore the observed effects $[23,64$, $78,85,116]$. In addition, slight or no further changes were seen for the NKG2D expression, when recombinant TGF-b was added to tumor exosomes, indicating that tumor exosomes alone can maximally activate the TGF1-dependent NKG2D down-regulation pathway $[23,78]$. Based on these observations, researchers have assumed that exosomal TGF $\beta$ may interact with TGF $\beta R I / I I$ receptors on the cell surface, inducing inhibitory downstream signals in NK cells that leads to the decreased NKG2D expression [23, 64]. This becomes evident as SMAD2/3 phosphorylation was observed to be increased in NK cells co-incubated with TGF $\beta+$ exosomes $[23,64]$. TGF-b containing exosomes were also shown to downregulate the expression of Tbet transcription factor in NK cells [23]. However, TGFßRI/II inhibitor (LY2109761) or TGF-b knockdown could decrease SMAD $2 / 3$ phosphorylation to the baseline levels $[23,64]$. These findings strongly support that tumor exosomes can deliver TGF-b to the surface of NK cells that is engaged with TGF $\beta$ RI/II and subsequently upregulates SMAD 2/3 phosphorylation and decreases Tbet expression levels, leading to the decreased NKG2D expression and abrogated cytolytic activity in NK cells [23, 64] (Fig. 3). Likewise, others have shown that TGF-b can be transferred to NK cells by oral cancer-derived exosomes (OCEXs) and extracellular vehicles (EVs)-derived from pancreatic cancer that activates the phosphorylation of Smad2/3 signaling pathway, ultimately resulting in NK cell dysfunction $[22,34]$. Besides, some experiments showed that exosomal TGF-b induces the phosphorylation of SMAD1/5/8 in NK cells, resulting in lower expression of NKG2D, where the addition of anti-TGF-b antibodies restored these effects [85] (Fig. 3). A recent study also found that acute lymphoblastic leukemia (ALL)-derived exosomes alter NK92-MI cells function mainly through signaling of the TGF-b pathway [36]. Observations revealed that ALL exosomes upregulate the expression of several genes related to the TGF-b signaling pathway, including MDS1 and EVI1, that enhances TGF-b signaling 


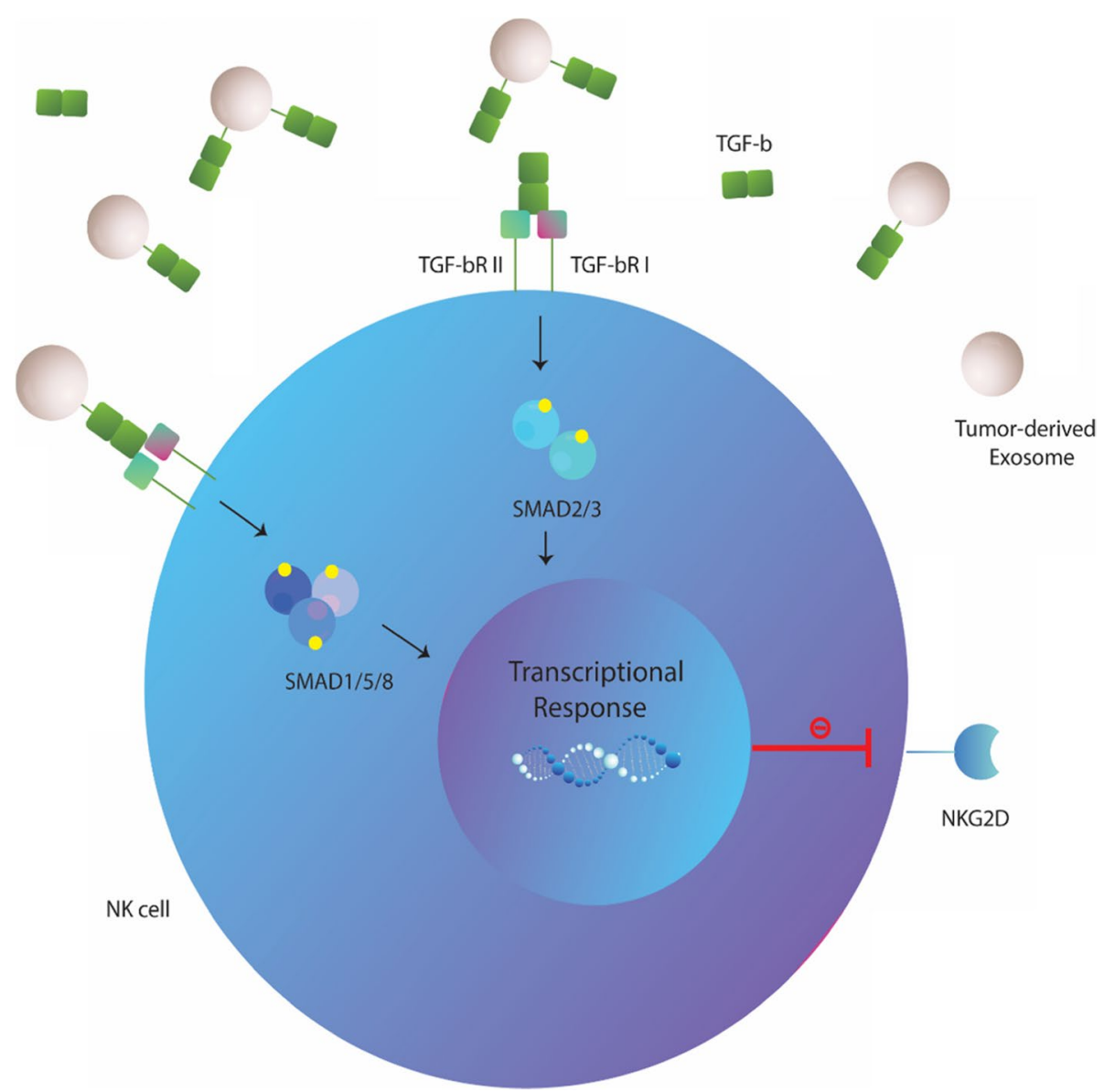

Fig. 3 Exosomal transforming growth factor-beta (TGF-b) induces NK cells dysfunction. Tumor-derived exosomes (TDEs) harbor higher levels of membrane-associated mature TGF-b that can be dissociated to increase TGF-b levels in the tumor microenvironment. Both membrane-bound and soluble forms of TGF-b (released from tumor exosomes) are capable of binding to TGF-bRI/TGF-bRII on NK cells that result in SMAD2/3 or SMAD1/5/8 phosphorylation, which are subsequently translated into the lower expression of NKG2D and associated activation of NK cells

and its inhibitory effects [36, 117]. Taken together, all these data suggest a central role for exosomal TGF-b in decreasing NKG2D expression and tumor-induced NK cells dysfunction.

Worth noting, exosomes derived from $\mathrm{T}$ (tumor) region had higher TGF-b than that from NT (nontumor) region [64]. On the other hand, TDEs isolated before, during and after chemotherapy exhibited different levels of active TGF-b (99), and only exosomes containing high levels of mature TGF-b were able to inhibit expression of NKG2D in purified normal human NK cells $[64,95]$. Such a data implies that the inhibitory effects of TGF- $\mathrm{b}+$ exosomes are more pronounced at tumor site and on tumor-infiltrating NK cells rather than circulating NK cells.

Furthermore, since hypoxic tumor microenvironment has been verified to modulate TGF-b signaling and exosomal cargo loading, researchers have also examined whether hypoxia can affect expression of
NK ligands and TGF-b on non-small cell lung cancer (NSCLC)-derived MVs [37]. Although, no significant changes were observed in expression of NK ligands on hypoxic TD-MVs, but interestingly, MVs isolated from hypoxic cells (hypoxic IGR-Heu and K562 tumor cells) had significantly higher levels of TGF-b compared to those from normoxic tumor cells [37]. Of particular note, treatment of NK-92 and NKD cells with MVs of hypoxic tumor cells dramatically decreased surface NKG2D expression, which was abolished by anti-TGFb blocking antibody [37]. Targeting vesicular TGF-b also restored the IFN $\gamma$ production by NK-92 and NKD cells. These results were consistent with the observations that hypoxic derived MVs had remarkably greater inhibitory effect on NKG2D expression in comparison to normoxic MVs [37]. Overall, it was concluded that hypoxia suppresses NK cells activity, in part, by inducing TGF-b sorting into MVs released by tumors, while the levels of particle-associated NKG2D ligands 
are somehow stable. This is somehow in line with the previous findings showed that exosomes isolated from tumors of higher stages exhibited more immunosuppressive cargo than those from early stages [37, 118]. Because hypoxia is a more common feature of advanced stage tumors, thus higher levels of TGF-b would be expected to present on TDEs with the tumor progression. Accordingly, it can be postulated that tumor progression (hypoxia condition) can strengthen the effects of exosomal TGF-b on NKG2D downregulation and tumor-associated NK cells dysfunction.

\section{Exosomal adenosine and glucose metabolism}

Adenosine (ADO) is a well-recognized inhibitor of immune cell functions [119-121]. As a part of fact, adenosine can interact with A2AR receptors on immune cells, inducing a cascade of downstream signals that upregulates cAMP and inhibits cellular function [120, 122-124]. Studies have shown that tumor exosomes carry CD39/CD73 actively contribute to the suppression of anti-tumor $\mathrm{T}$ cells and the production of ADO by Treg cells [125]. In the same direction, NK-92 cells were observed to produce significant levels of $\mathrm{ADO}$, inosine and hypoxanthine in the presence of exogenous ATP and CD39+/CD73 + AML exosomes [23]. It was noted that AML exosomes are able to convert exogenous ATP into ADO, however, although NK-92 cells express CD39/CD73 pair and A2AR, but they do not produce ADO in the presence of exogenous ATP. Strikingly, in the presence of tumor exosomes, NK cells are able to produce ADO from exogenous ATP. Therefore, it can be inferred that exposure to exosomal CD39/CD73 forces NK cells to produce ADO, and because NK-92 cells carry A2ARs, it is very likely that autocrine signaling of ADO or inosine binding to the A2ARs expressed on NK-92 cells may, in part, responsible for a loss of function in NK-92 cells [126] (Fig. 1h). Glioblastoma-derived exosomes (GBex) have also been shown to carry CD39 and CD73, and ADO produced by these exosomal proteins is assumed to be partly responsible for GBex-mediated NK cell dysfunction [63]. In spite of adenosine, nutrient uptake and glucose metabolism are also important for proper NK cell responses [127, 128]. CD71 (transferrin receptor), CD98 (large neutral amino acid transporter), and 2-NBDG incorporation ability are three commonly-used metabolic parameters in NK cells [34]. However, pancreatic cancer cells (L3.6pl)-derived EVs were shown to significantly reduce the expression of CD71 and CD98 in NK cells and their glucose uptake capability [34]. Such findings underscore the importance of TDEs in mediating metabolic reprograming of NK cells (Fig. 1h).

\section{Exosomal fas-I, survivin, B7-H3 and PD-L1}

Increasing evidence shows that TDEs harbor a plethora of membrane-associated proteins that are crucially participated in tumor-immune escape [42, 129]. Several studies have demonstrated that TDEs carry Fas-L can induce apoptosis in TCD8+ cells [130-135]. Others have also shown that tumor cells actively release Fas-L bearing EVs to kill Fas-expressing cells in TME, including NK cells [63]. In a research on lymphoma, it was found that lymphoma-derived exosomes are enriched in Fas-L and Survivin, a member of the inhibitor of apoptosis (IAP) proteins, but did not contain MICA/B and TGF-b [86]. Findings revealed that treatment with the lymphoma-derived exosomes downregulate the expression of NKG2D on NK cells and decrease protein levels of perforin, granzyme B, TNF- $\alpha$, and IFN- $\gamma$ which might be Fas-L/Survivin dependent [86].

$\mathrm{B} 7-\mathrm{H} 3$, a member of the B7-family proteins, is another checkpoint molecule has been shown to enforce immunosuppression in a variety to tumors [136-138]. Previously, it was found that glioblastoma cells secret B7-H3 in exosomal manner that can suppress NK-mediated tumor lysis [87]. Additionally, the majority of most recent studies investigating the roles of TDEs in cancer biology pointed out that exosomes also play a major role in tumor-immune escape through PD-L1/PD1 axis [51, 139-141]. It was demonstrated that TDEs carry functional isoform of PD-L1 that robustly act against antitumor immunity [33, 51]. Furthermore, it has been shown that PD-L1 positive exosomes counteract the benefits of anti-PD-1/PD-L1 mAb therapy $[139,142]$. Since activated NK cells also express $\mathrm{PD}-1$, it is thus conceivable that PD-L1 bearing tumor exosomes exert inhibitory effect on NK cells [143]. In this regard, a recent study showed that melanoma-derived exosomes induce NK cell dysfunction partly through PD-L1 expression [88]. However, controversially, PD-L1 + exosomes from plasma of AML patients have been suggested to not contribute to the suppression of NK-92 activity [23]. Overall, these findings support the view that tumor exosomes carry various biologically-active molecules with the potential to activate inhibitory molecular pathways in recipient cells, including NK cells (Fig. 2).

\section{Exosomal RNAs}

In addition to proteins, TDEs contain mRNAs, microRNAs and lncRNAs that can be taken-up by other cells, including NK cells and alter their function [144-147]. Investigating the effects of circulating exosomes on hepatocellular carcinoma (HCC) development and recurrence after living donor liver transplantation (LDLT), it was found that hepatoma-derived exosomes contain high 
levels of miR-92b [89]. Experimental results revealed that exosomes derived from miR-92b overexpressing Hep3B cells are also rich in miR-92b. In particular, treatment with miR-92b containing exosomes remarkably induced miR-92b expression in NK-92 cells, indicating that tumors actively transfer inhibitory biomolecules, including miRNAs, to infiltrating NK cells via exosomes [89]. Because of its pivotal role in NK cells function, researchers have examined whether exosomal miR92b can alter CD69 expression on NK cells. Subsequent results showed that transfer of miR-92b via TDEs could significantly inhibit CD69 expression on NK-92 cells and reduced their cytotoxicity against parental Hep3B tumor cells. Furthermore, the overexpression of miR-92b was found to be associated with the enhanced migration of liver cancer cell lines [89]. The same results were also repeated by primary NK cells from mouse and mouse lymphoma YAC-1 cells. These results demonstrate that tumor-derived circulating exosomes are able to transfer their miRNA content into tumor-infiltrating immune cells, including NK cells, and thereby suppress their antitumor activities in favor of tumor progression. In another research on NSCLC, the role of hypoxic tumor-derived MVs in transferring miRNAs to mediate NK cell dysfunction has been investigated [37]. Profiling MVs from both normoxic and hypoxic tumor cells revealed the presence of miRNAs. Of particular note, hypoxic MVs were found to have higher amounts of miR-210 and miR-23a compared to normoxic MVs. Further findings showed that hypoxic MVs containing miR-23a could impair NK cells cytolytic activity by downregulating CD107a, while miRNA-210 did not affect NK cells function [37]. Moreover, miR-23a containing exosomes was observed to not alter the receptor expression patterns as well as the expression levels of IFNY and granzyme B in NK cells, suggesting that its ability to suppress NK cells cytotoxicity is most likely related to its effect on CD107a expression. This was confirmed as the hypoxic MVs-mediated decrease in the percentage of CD107a and IFN $\gamma$-positive NK cells was reversed when MVs were transfected with pre-miR-23a [37] (Fig. 1g).

Others have also shown that HCC exosomes contain high levels of ubiquitin-like with PHD and ring finger domain 1 RNA (circUHRF1) comparable to that seen in human HCC tissues [90]. It has been demonstrated that circUHRF1 is secreted in an exosomal manner into plasma of HCC patients mainly by tumor cells. Moreover, circUHRF1 was found to inhibit IFN- $\gamma$ and TNF- $\alpha$ secretion by NK cells and high levels of plasma exosomal circUHRF1 is closely associated with a decreased proportion of NK cell and their decreased infiltration into tumor microenvironment [90]. Furthermore, circUHRF1 was shown to drive resistance to anti-PD1 therapy in HCC patients and inhibits NK cells function by enhancing TIM-3 expression via degradation of miR-449c-5p [90]. A most recent study also showed that exosomal lncRNAs play major roles in exosome-mediated immune escape of colorectal cancer (CRC) from killing by NK cells [91]. Based on the results, exosomes derived from an epithelial-mesenchymal transition (EMT) model of SW480 cells were able to suppress the proliferation, cytotoxicity, production of IFN-g and secretion of the perforin and granzyme B of NK cells [91]. Further surveys showed that these exosomes contain lncRNA-SNHG10 that mediates the decreased viability and suppression of NK cells [91]. Transcriptome sequencing showed an upregulation of 114 genes in NK cells treated with exosomes containing lncRNA-SNHG10, including inhibin subunit beta $\mathrm{C}$ (INHBC), which is involved in the TGF-b signaling pathway. Putting these findings together, it can be postulated that TDEs act as a major mediator of tumor-associated NK cells dysfunction, that partly rest on their ability to transfer RNAs (Fig. 11g).

\section{Clinical significance and therapeutic approaches}

NK cells are increasingly proven as a promising tool for cancer treatment, especially blood malignancies $[17,148$, 149]. There are also great numbers of ongoing clinical trials investigating the efficacy of NK cell immunotherapy in treating solid tumors $[69,150,151]$. However, recently in a study on AML patients, it was revealed that circulating exosomes derived from tumor cells counteract the beneficial effects of adoptive NK-92 cell therapy [23] (Fig. 4a). As a fact, NK cells are also involved in anti-tumor immunity by a well-known antibody-dependent cellular cytotoxic (ADCC) process [152-154]. However, strikingly, previous studies have shown that tumor exosomes abolish the ADCC activity of NK cells [155]. For example, it has been shown that HER2 expressing exosomes act as a decoy to protect cancer cells from ADCC-mediated by NK cells. Such findings support the notion that tumor exosomes crucially devastate the therapeutic effects of NK cell-based therapy and monoclonal antibodies (mAbs) [155] (Fig. 4b). On this basis, as reviewed elsewhere, great efforts have been made in recent years to inhibit/remove circulating tumor exosomes as adjunctive therapy for cancer $[14,156-158]$. It seems that targeting exosomes can improve anti-tumor immune responses and therapeutic effects of currently available immunotherapies [14, 156] (Fig. 4d).

On the other hand, there are shreds of evidence indicating that adding IL-15 undoes the inhibitory effects of TDEs on NK cells. A previous study showed that addition of IL-15 to cocultures of MVs isolated from sera of AML patients with NK cells from normal donors significantly abrogated the MVs-mediated suppression of NK 


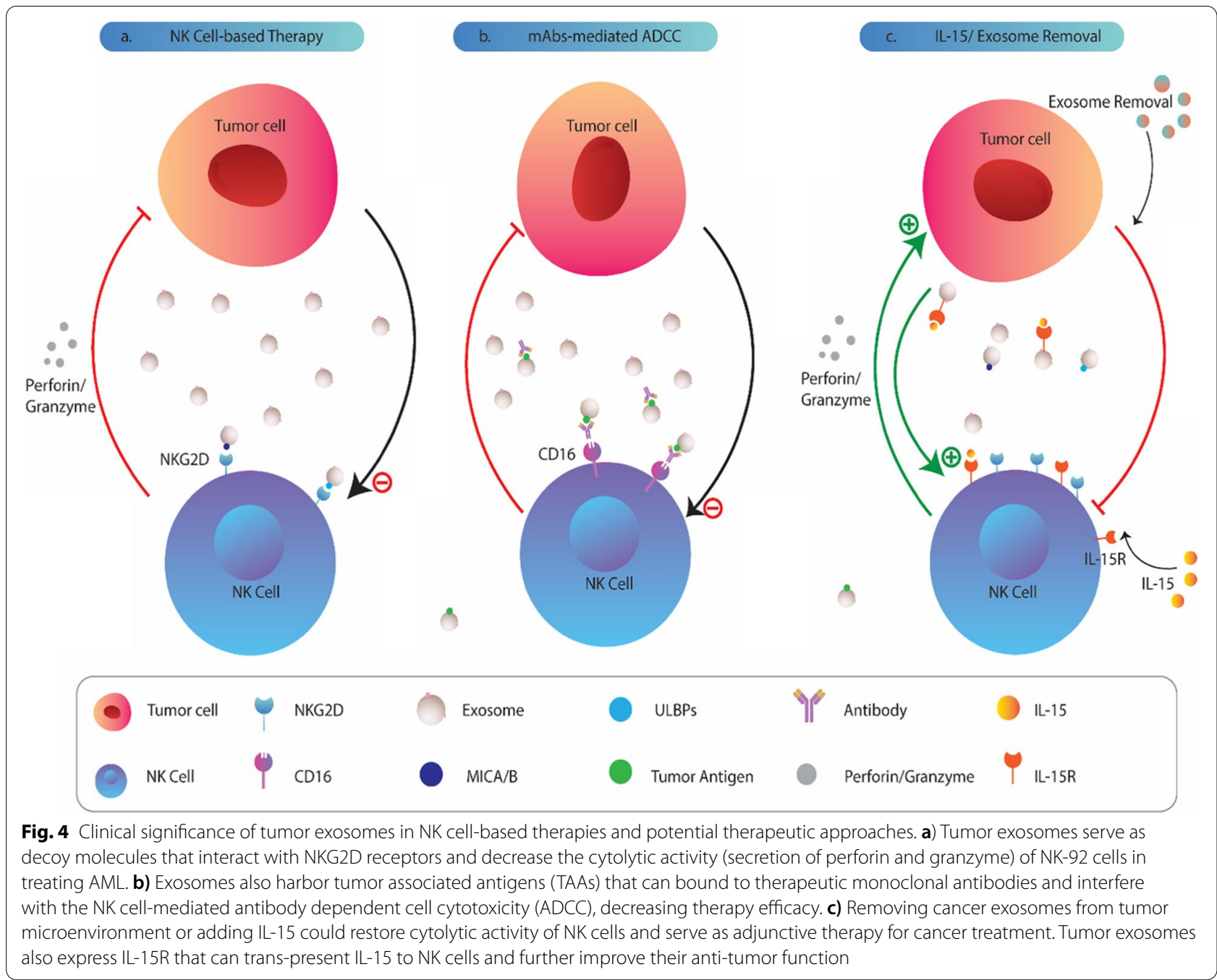

cell activity [85]. As mentioned previously, co-incubation of NK cells with MVs from AML patients up-regulates phospho-SMAD expression. However, the pre-treatment of NK cells with IL-15 followed by co-incubation with MVs derived from sera of AML patients prevented MVs-induced phosphorylation of the SMAD pathway [85]. Moreover, in the presence of IL-15, the expression level of NKG2D was shown to remain unchanged in NK cells treated with MVs [85]. Similarly, it has been shown that tumor exosomes could impair IL-15-mediated upregulation of NKG2D [78]. To clarify these observations, researchers have treated healthy donor PBLs with various concentrations of IL-15 either in the presence or absence of tumor exosomes [78]. The findings showed that in the absence of IL-15, tumor exosomes induce a significant reduction in NKG2D expression, but adding IL-15 could abolish the effect of exosomes and restore NKG2D to the baseline levels [78]. Confirming the above results, interesting findings from another study showed that low doses of chemotherapeutic agents, such as melphalan, could induce multiple myeloma cells to trans-present IL-15 to NK cells in an exosomal manner [26]. Detailed experiments revealed that both IL-15R and IL15 present on exosomes from melphalan-treated MM cells, where exosomal IL-15R mediate trans-presentation of IL-15 and can induce NK cells activation and proliferation [26]. These results are a proof of concept that IL-15 reverses the inhibition of NKG2D expression-mediated by tumor exosomes and protects NK cells from inhibitory effects of exosome-associated TGF-b (Fig. 4d).

\section{Perspectives and concluding remarks}

It is clear from the studies examining the effects of TDEs on NK cells thus far that, as it has been described for other anti-tumor immune cells, cancer exosomes are important players of immunosuppression in tumor bearing hosts. Furthermore, it is strongly believed that these virus-sized particles interfere with the immunotherapies 
and induce resistance to chemotherapies [159, 160]. The concept of exosome inhibition/removal has gained prominence but, as we have reviewed elsewhere, it is still far from the clinical practice [14, 157]. However, despite that, it seems that adding IL-15 to immunotherapies, including NK cell-based therapies, could add to their benefits, in part, through interfering with the dampening effects of TDEs [156]. This notion is supported by the several clinical trials indicating that combination of IL-15 with NK cells or other immunotherapies augments the therapy effects and could remarkably increase remission [161]. On the other hand, adding anti-TGF-b, to interfere with exosomal levels of this protein, would also enhance therapy efficiency [162]. This becomes evident, as it has been shown that inhibiting TGF-b could improve the therapeutic efficacy of adoptive NK cell therapy [162164]. Engineering exosomes to express HSP-70, IL-2 and IL12 or surface anchorage of staphylococcus enterotoxin A (SEA) onto TDEs have also been shown to enhance the anti-tumor activity of NK cells [27, 165-167]. Some reports also show that exosomes from tumor cells under genotoxic stress and epigenetic drug treatment or postirradiation exosomes could enhance NK cells anti-tumor responses $[25,26,30,168,169]$. Thus, it seems interesting to employ engineered exosomes with customized cargo or some anti-cancer drugs, as an adjunctive treatment, to improve NK cells cytolytic activity. On the other hand, in spite of several biomolecules discussed in this review, there might be also some other unknown/less studied exosomal molecules that are involved in NK cell dysfunction in tumors [1, 170-172]. Therefore, further research are warranted to study the molecular basis of TDEs-mediated NK cells impairments. In summary, with deep understanding of the pathological roles and mechanisms underlie the TDE-mediated NK cells dysfunction; we would be able to further improve the therapeutic potential of NK cells, as well as other immunotherapies, in treating cancers.

\footnotetext{
Abbreviations

TDEs: Tumor-derived exosomes; NK cell: Natural killer cell; IncRNAs: Long non-coding RNAs; miRNAs: MicroRNAs; DCs: Dendritic cells; CTL: Cytotoxic T lymphocyte; KIR: Killer inhibitory receptor; $\mathrm{MHCl}$ : Major histocompatibility complex I;; MVs: Microvesicles; CXCL4: Chemokine (C-X-C motif) ligand 4; CXCL7: Chemokine (C-X-C motif) ligand 7; AML: Acute myeloid leukemia; CCL5: C-C Motif Chemokine Ligand 5; CXCR3: C-X-C Motif Chemokine Receptor 3; IL-2: Interleukin 2; IL-2R: Interleukin 2 receptor; MM-EXs: Multiple myeloma-derived exosomes; EVs: Extracellular vesicles; CSC: Cancer stem cell; OCEXs: Oral cancer exosomes; TD-MVs: Tumor-derived microvesicles; HNC: Head and neck cancer; GBex: Glioblastoma exosome; ccRCC: Clear cell renal cell carcinoma; IFNY: Interferon-gamma; mRNA: Messenger RNA; PBMCs: Peripheral blood mononuclear cells; CRPC: Castration-resistant prostate cancer; PC: Prostate cancer; MICA/B: MHC class I-related chain A/B; EBV-B: Epstein bar virus-B; ULBP: UL16 binding proteins; mAbs: Monoclonal antibodies; EOC: Epithelial ovarian cancer; TGF-b: Transforming growth factor-beta; TGF-bRI/II:Transforming growth factor beta receptor I/II; (NSCLC: Non-small cell lung cancer; ADO: Adenosine; A2ARs: Adenosine A2A receptors; Fas-L:
}

Fas-ligand; PD-L1: Programmed death-ligand 1; IAP: Inhibitor of apoptosis; TCD8 + : CD8 + T lymphocyte; TNF-a: Tumor necrosis factor-alpha; circUHRF1: Ubiquitin-like with PHD and ring finger domain 1 RNA; HCC: Hepatocellular carcinoma; TIM-3: T cell immunoglobulin and mucin domain-containing protein 3; ADCC: Antibody-dependent cellular cytotoxicity.

\section{Acknowledgements}

This study was supported by grants from Isfahan University of Medical Sciences, Isfahan, Iran; and Cancer Research Center, Shahid Beheshti University of Medical Sciences, Tehran, Iran.

\section{Authors' contributions}

All authors contributed to writing this paper. All authors read and approved the final manuscript.

\section{Funding}

Not applicable

Availability of data and materials

Not applicable

\section{Declarations}

Ethics approval and consent to participate

Not applicable

Consent for publication

Not applicable

\section{Competing interests}

The authors declare that they have no competing interests.

\section{Author details}

'Department of Immunology School of Medicine, Isfahan University of Medical Sciences, Isfahan, Iran. ${ }^{2}$ Department of Immunology School of Public Health, Tehran University of Medical Sciences, Tehran, Iran. ${ }^{3}$ Department of Medical Genetics School of Medicine, Tehran University of Medical Sciences, Tehran, Iran. ${ }^{4}$ Student Research Committee, Department of Medical Genetics, School of Medicine Shahid, Beheshti University of Medical Sciences, Tehran, Iran. ${ }^{5}$ Surgical Oncologist Cancer Research Center, Shahid Beheshti University of Medical Sciences, Tehran, Iran. ${ }^{6}$ Department of Biochemistry and Molecular Biology, LSUHSC School of Medicine, New Orleans, USA.

Received: 6 Auqust 2021 Accepted: 26 December 2021

Published online: 14 January 2022

\section{References}

1. Kano A. Tumor cell secretion of soluble factor (s) for specific immunosuppression. Sci Rep. 2015;5:1-8.

2. LuT, Sathe SS, Swiatkowski SM, Hampole CV, Stark GR. Secretion of cytokines and growth factors as a general cause of constitutive NF k B activation in cancer. Oncogene. 2004;23:2138-45.

3. Briukhovetska D, Dörr J, Endres S, Libby P, Dinarello CA, Kobold S. Interleukins in cancer: from biology to therapy. Nat Rev Cancer 2021:21:481-99.

4. da Cunha BR, Domingos C, Stefanini ACB, Henrique T, Polachini GM, Castelo-Branco P, Tajara EH. Cellular interactions in the tumor microenvironment: the role of secretome. J Cancer. 2019;10:4574.

5. Su C, Zhang J, Yarden Y, Fu L. The key roles of cancer stem cell-derived extracellular vesicles. Signal Transduct Target Ther. 2021;6:1-15.

6. Xu R, Rai A, Chen M, Suwakulsiri W, Greening DW, Simpson RJ. Extracellular vesicles in cancer-implications for future improvements in cancer care. Nat Rev Clin Oncol. 2018;15:617-38.

7. Dai J, Su Y, Zhong S, Cong L, Liu B, Yang J, Tao Y, He Z, Chen C, Jiang Y. Exosomes: key players in cancer and potential therapeutic strategy. Signal Transduct Target Ther. 2020;5:1-10.

8. Möller A, Lobb RJ. The evolving translational potential of small extracellular vesicles in cancer. Nat Rev Cancer. 2020;20:697-709. 
9. Mashouri L, Yousefi H, Aref AR. mohammad Ahadi A, Molaei F, Alahari SK: Exosomes: composition, biogenesis, and mechanisms in cancer metastasis and drug resistance. Mol Cancer. 2019;18:75.

10. Tan Y, Luo X, Lv W, Hu W, Zhao C, Xiong M, Yi Y, Wang D, Wang Y, Wang H. Tumor-derived exosomal components: the multifaceted roles and mechanisms in breast cancer metastasis. Cell Death Dis. 2021;12:1-18.

11. Bae S, Brumbaugh J, Bonavida B. Exosomes derived from cancerous and non-cancerous cells regulate the anti-tumor response in the tumor microenvironment. Genes Cancer. 2018:9:87.

12. Marar C, Starich B, Wirtz D. Extracellular vesicles in immunomodulation and tumor progression. Nat Immunol. 2021;22:560-70.

13. Liu J, Wu S, Zheng X, Zheng P, Fu Y, Wu C, Lu B, Ju J, Jiang J. Immune suppressed tumor microenvironment by exosomes derived from gastric cancer cells via modulating immune functions. Sci Rep. 2020;10:1-12.

14. Hosseini R, Asef-Kabiri L, Yousefi H, Sarvnaz H, Salehi M, Akbari ME, Eskandari N. The roles of tumor-derived exosomes in altered differentiation, maturation and function of dendritic cells. Mol Cancer. 2021:20:1-17.

15. Whiteside TL. Immune modulation of T-cell and NK (natural killer) cell activities by TEXs (tumour-derived exosomes). Biochem Soc Trans. 2013:41:245-51.

16. Huntington ND, Cursons J, Rautela J. The cancer-natural killer cell immunity cycle. Nat Rev Cancer. 2020:20:437-54.

17. Wu S-Y, Fu T, Jiang Y-Z, Shao Z-M. Natural killer cells in cancer biology and therapy. Mol Cancer. 2020;19:1-26.

18. Sun C. Sun H-y, Xiao W-h, Zhang C, Tian Z-g: Natural killer cell dysfunction in hepatocellular carcinoma and NK cell-based immunotherapy. Acta Pharmacol Sin. 2015;36:1191-9.

19. Batista IA, Quintas ST, Melo SA. The Interplay of Exosomes and NK Cells in Cancer Biology. Cancers. 2021;13:473.

20. Vulpis E, Soriani A, Cerboni C, Santoni A, Zingoni A. Cancer exosomes as conveyors of stress-induced molecules: new players in the modulation of NK cell response. Int J Mol Sci. 2019;20:611.

21. Soriani A, Vulpis E, Cuollo L, Santoni A, Zingoni A. Cancer extracellular vesicles as novel regulators of NK cell response. Cytokine Growth Factor Rev. 2020;51:19-26.

22. Zhu X, Qin X, Wang X, Wang Y, Cao W, Zhang J, Chen W. Oral cancer cellderived exosomes modulate natural killer cell activity by regulating the receptors on these cells. Int J Mol Med. 2020;46:2115-25.

23. Hong C-S, Sharma P, Yerneni SS, Simms P, Jackson EK, Whiteside TL, Boyiadzis $\mathrm{M}$. Circulating exosomes carrying an immunosuppressive cargo interfere with cellular immunotherapy in acute myeloid leukemia. Scientific Reports. 2017;7:14684.

24. Gastpar R, Gehrmann M, Bausero MA, Asea A, Gross C, Schroeder JA, Multhoff GJCr. Heat shock protein 70 surface-positive tumor exosomes stimulate migratory and cytolytic activity of natural killer cells. Cancer Res. 2005;65:5238-47.

25. Vulpis E, Cecere F, Molfetta R, Soriani A, Fionda C, Peruzzi G, Caracciolo G, Palchetti S, Masuelli L, Simonelli LJO. Genotoxic stress modulates the release of exosomes from multiple myeloma cells capable of activating NK cell cytokine production: Role of HSP70/TLR2/NF-kB axis. Oncoimmunology. 2017:6:e1279372

26. Borrelli C, Ricci B, Vulpis E, Fionda C, Ricciardi MR, Petrucci MT, Masuelli L, Peri A, Cippitelli M, Zingoni AJCir. Drug-induced senescent multiple myeloma cells elicit NK cell proliferation by direct or exosome-mediated IL15 trans-presentation. Cancer Immunol Res. 2018;6:860-9.

27. Xie Y, Bai O, Zhang H, Yuan J, Zong S, Chibbar R, Slattery K, Qureshi M, Wei Y, Deng YJJoc. medicine m: Membrane-bound HSP70-engineered myeloma cell-derived exosomes stimulate more efficient CD8+ CTLand NK-mediated antitumour immunity than exosomes released from heat-shocked tumour cells expressing cytoplasmic HSP70. J Cell Mol Med. 2010;14:2655-66.

28. Daßler-Plenker J, Reiners KS, van den Boorn JG, Hansen HP, Putschli B, Barnert S, Schuberth-Wagner C, Schubert R, Tüting T, Hallek M, et al. RIG-I activation induces the release of extracellular vesicles with antitumor activity. Oncoimmunology. 2016;5:e1219827.

29. Pogge von Strandmann E, Simhadri VR, von Tresckow B, Sasse S, Reiners KS, Hansen HP, Rothe A, Böll B, Simhadri VL, Borchmann P, et al. Human leukocyte antigen-B-associated transcript 3 is released from tumor cells and engages the NKp30 receptor on natural killer cells. Immunity. 2007;27:965-74.

30. Jella KK, Nasti TH, Li Z, Lawson DH, Switchenko JM, Ahmed R, Dynan WS, Khan MK. Exosome-Containing Preparations From Postirradiated Mouse Melanoma Cells Delay Melanoma Growth In Vivo by a Natural Killer Cell-Dependent Mechanism. Int J Radiat Oncol Biol Phys. 2020;108:104-14.

31. Wang Y, Qin X, Zhu X, Chen W, Zhang J, Chen W. Oral cancer-derived exosomal NAP1 enhances cytotoxicity of natural killer cells via the IRF-3 pathway. Oral Oncol. 2018;76:34-41.

32. Bennit HRF, Gonda A, Oppegard LJ, Chi DP, Khan S, Wall NR. Uptake of lymphoma-derived exosomes by peripheral blood leukocytes. Blood and lymphatic cancer: targets and therapy. 2017;7:9.

33. Morrissey SM, Yan J. Exosomal PD-L1: Roles in Tumor Progression and Immunotherapy. Trends Cancer. 2020;6:550-58.

34. Zhao J, Schlößer HA, Wang Z, Qin J, Li J, Popp F, Popp MC, Alakus H, Chon S-H, Hansen HP. Tumor-derived extracellular vesicles inhibit natural killer cell function in pancreatic cancer. Cancers. 2019:11:874.

35. Liu C, Yu S, Zinn K, Wang J, Zhang L, Jia Y, Kappes JC, Barnes S, Kimberly RP, Grizzle WE. Murine mammary carcinoma exosomes promote tumor growth by suppression of NK cell function. J Immunol. 2006;176:1375-85.

36. Yu H, Huang T, Wang D, Chen L, Lan X, Liu X, Chen K, He H, Li S, Zhou YJB. Acute lymphoblastic leukemia-derived exosome inhibits cytotoxicity of natural killer cells by TGF- $\beta$ signaling pathway. 3 Biotech. 2021;11:1-10.

37. Berchem G, Noman MZ, Bosseler M, Paggetti J, Baconnais S, Le Cam E, Nanbakhsh A, Moussay E, Mami-Chouaib F, Janji B. Hypoxic tumor-derived microvesicles negatively regulate NK cell function by a mechanism involving TGF- $\beta$ and miR23a transfer. Oncoimmunology. 2016:5:e1062968.

38. Wen SW, Sceneay J, Lima LG, Wong CS, Becker M, Krumeich S, Lobb RJ, Castillo V, Wong KN, Ellis SJCr. The biodistribution and immune suppressive effects of breast cancer-derived exosomes. Cancer Res. 2016;76:6816-27.

39. Hazan-Halevy I, Rosenblum D, Weinstein S, Bairey O, Raanani P. Peer DJCl: Cell-specific uptake of mantle cell lymphoma-derived exosomes by malignant and non-malignant B-lymphocytes. Cancer Lett. 2015;364:59-69.

40. Huyan T, Yongyong D, Huang Q, Huang Q, Qi L. Uptake characterization of tumor cell-derived exosomes by natural killer cells. Iran J Public Health. 2018:47:803.

41. Keller S, König A-K, Marmé F, Runz S, Wolterink S, Koensgen D, Mustea A, Sehouli J. Altevogt PJCl: Systemic presence and tumor-growth promoting effect of ovarian carcinoma released exosomes. Cancer Lett. 2009;278:73-81.

42. Whiteside T. Exosomes carrying immunoinhibitory proteins and their role in cancer. Clin Exp Immunol. 2017;189:259-67.

43. Muller L, Mitsuhashi M, Simms P, Gooding WE, Whiteside TL. Tumorderived exosomes regulate expression of immune function-related genes in human T cell subsets. Sci Rep. 2016;6:1-13.

44. Muller L, Simms P, Hong C-S, Nishimura MI, Jackson EK, Watkins SC, Whiteside TL. Human tumor-derived exosomes (TEX) regulate Treg functions via cell surface signaling rather than uptake mechanisms. Oncoimmunology. 2017;6:e1261243.

45. Sung BH, Weaver AMJCa. migration: Exosome secretion promotes chemotaxis of cancer cells. Cell Adh Migr. 2017;11:187-95.

46. Sung BH, Ketova T, Hoshino D, Zijlstra A. Weaver AMJNc: Directional cell movement through tissues is controlled by exosome secretion. Nat Commun. 2015;6:1-14.

47. Liu Y, Xiang X, Zhuang X, Zhang S, Liu C, Cheng Z, Michalek S, Grizzle W, Zhang H-GJTAjop. Contribution of MyD88 to the tumor exosomemediated induction of myeloid derived suppressor cells. Am J Pathol. 2010;176:2490-9.

48. Park EJ, Myint PK, Appiah MG, Worawattananutai P, Inprasit J, Prajuabjinda O, Soe ZY, Gaowa A, Kawamoto E, Shimaoka MJB. reports b: Ligand-competent fractalkine receptor is expressed on exosomes. Biochem Biophys Rep. 2021;26:100932.

49. Chen T, Guo J, Yang M, Zhu X. Cao XJTJol: Chemokine-containing exosomes are released from heat-stressed tumor cells via lipid 
raft-dependent pathway and act as efficient tumor vaccine. J Immunol. 2011;186:2219-28.

50. Li M, Lu Y, Xu Y, Wang J, Zhang C, Du Y, Wang L, Li L, Wang B, Shen JJG. : Horizontal transfer of exosomal CXCR4 promotes murine hepatocarcinoma cell migration, invasion and lymphangiogenesis. Gene. 2018;676:101-9.

51. Kim DH, Kim H, Choi YJ, Kim SY, Lee J-E, Sung KJ, Sung YH, Pack C-G. Jung M-K, Han B: Exosomal PD-L1 promotes tumor growth through immune escape in non-small cell lung cancer. Exp Mol Med. 2019;51:1-13

52. Liu Y, Gu Y, Cao X. The exosomes in tumor immunity Oncoimmunology. 2015:4:e1027472

53. Olejarz W, Dominiak A, Żołnierzak A, Kubiak-Tomaszewska G, Lorenc T. Tumor-derived exosomes in immunosuppression and immunotherapy. Journal of immunology research. 2020;2020:6272498.

54. Clayton A, Mitchell JP, Mason MD, Tabi ZJCr. Human tumor-derived exosomes selectively impair lymphocyte responses to interleukin-2. Cancer Res. 2007;67:7458-66.

55. Moloudizargari M, Redegeld F, Asghari MH, Mosaffa N, Mortaz E. Longchain polyunsaturated omega-3 fatty acids reduce multiple myeloma exosome-mediated suppression of NK cell cytotoxicity. DARU Journal of Pharmaceutical Sciences. 2020;28:647-59.

56. Habif $G$, Crinier A, André P, Vivier E, Narni-Mancinelli E. Targeting natural killer cells in solid tumors. Cell Mol Immunol. 2019;16:415-22.

57. Stojanovic A, Cerwenka A. Natural killer cells and solid tumors. J Innate Immun. 2011;3:355-64.

58. Ruiu R, Tarone L, Rolih V, Barutello G, Bolli E, Riccardo F, Cavallo F, Conti L. Cancer stem cell immunology and immunotherapy: Harnessing the immune system against cancer's source. Prog Mol Biol Transl Sci. 2019;164:119-88.

59. Liu S, Galat V, Galat Y, Lee YKA, Wainwright D, Wu J. NK cell-based cancer immunotherapy: From basic biology to clinical development. J Hematol Oncol. 2021;14:1-17.

60. Katsiougiannis S, Chia D, Kim Y, Singh RP, Wong DTJTFJ. Saliva exosomes from pancreatic tumor-bearing mice modulate NK cell phenotype and antitumor cytotoxicity. FASEB J. 2017;31:998-1010.

61. Hong C-S, Danet-Desnoyers G, Shan X, Sharma P, Whiteside TL, Boyiadzis M. Human acute myeloid leukemia blast-derived exosomes in patient-derived xenograft mice mediate immune suppression. Experimental hematology. 2019;76:60-66.e62.

62. Hong C-S, Funk S, Muller L, Boyiadzis M, Whiteside TL. Isolation of biologically active and morphologically intact exosomes from plasma of patients with cancer. Journal of extracellular vesicles. 2016;5:29289.

63. Azambuja JH, Ludwig N, Yerneni S, Rao A, Braganhol E, Whiteside TL. Molecular profiles and immunomodulatory activities of glioblastomaderived exosomes. Neuro-oncology advances. 2020;2:vdaa056.

64. Xia Y, Zhang Q, Zhen Q, Zhao Y, Liu N, Li T, Hao Y, Zhang Y, Luo C, Wu $X$. Negative regulation of tumor-infiltrating NK cell in clear cell renal cell carcinoma patients through the exosomal pathway. Oncotarget. 2017:8:37783

65. Othman N, Jamal R, Abu N. Cancer-derived exosomes as effectors of key inflammation-related players. Front Immunol. 2019;10:2103.

66. Zhang Y, Huang B. The Development and Diversity of ILCS, NK Cells and Their Relevance in Health and Diseases. Adv Exp Med Biol. 2017;1024:225-44.

67. Abel AM, Yang C, Thakar MS, Malarkannan S. Natural killer cells: development, maturation, and clinical utilization. Front Immunol. 1869;2018:9.

68. Chen J-h, Xiang J-y, Ding G-p, L-pJJoZU-SB C. Cholangiocarcinomaderived exosomes inhibit the antitumor activity of cytokine-induced killer cells by down-regulating the secretion of tumor necrosis factor-a and perforin. J Zhejiang Univ Sci B. 2016;17:537-44.

69. Shin MH, Kim J, Lim SA, Kim J, Kim S-J, Lee KM. NK cell-based immunotherapies in cancer. Immune network. 2020:20:e14.

70. Lanier LL. On guard_-activating NK cell receptors. Nat Immunol. 2001:2:23-7.

71. Paul S, Lal G. The molecular mechanism of natural killer cells function and its importance in cancer immunotherapy. Front Immunol. 2017:8:1124.

72. Cheent K, Khakoo SI. Natural killer cells: integrating diversity with function. Immunology. 2009:126:449-57.
73. Brostjan C, Sobanov Y, Glienke J, Hayer S, Lehrach H, Francis F, Hofer E. The NKG2 natural killer cell receptor family: comparative analysis of promoter sequences. Genes Immun. 2000;1:504-8.

74. Zhang X, Feng J, Chen S, Yang H, Dong Z. Synergized regulation of NK cell education by NKG2A and specific Ly49 family members. Nat Commun. 2019;10:1-12.

75. Bald T, Krummel MF, Smyth MJ, Barry KCJNi. The NK cell-cancer cycle: advances and new challenges in NK cell-based immunotherapies. Nat Immunol. 2020;21:835-47.

76. Mincheva-Nilsson L, Baranov V. Cancer exosomes and NKG2D receptorligand interactions: impairing NKG2D-mediated cytotoxicity and antitumour immune surveillance. Semin Cancer Biol. 2014;28:24-30.

77. Hong CS, Muller L, Boyiadzis M, Whiteside TLJPo. Isolation and characterization of $\mathrm{CD} 34+$ blast-derived exosomes in acute myeloid leukemia. PloS one. 2014;9:e103310.

78. Clayton A, Mitchell JP, Linnane S, Mason MD, Tabi Z. Human tumorderived exosomes down-modulate NKG2D expression. J Immunol. 2008;180:7249-58.

79. Lundholm M, Schröder M, Nagaeva O, Baranov V, Widmark A, MinchevaNilsson L, Wikström P. Prostate tumor-derived exosomes down-regulate NKG2D expression on natural killer cells and CD8+ T cells mechanism of immune evasion. PloS one. 2014;9:e108925.

80. Baginska J, Viry E, Paggetti J, Medves S, Berchem G, Moussay E, Janji B. The critical role of the tumor microenvironment in shaping natural killer cell-mediated anti-tumor immunity. Front Immunol. 2013;4:490.

81. López-Cobo S, Campos-Silva C, Moyano A, Oliveira-Rodríguez M, Paschen A, Yáñez-Mó M, Blanco-López MC, Valés-Gómez M. Immunoassays for scarce tumour-antigens in exosomes: detection of the human NKG2D-Ligand, MICA, in tetraspanin-containing nanovesicles from melanoma. Journal of nanobiotechnology. 2018;16:1-12.

82. Ashiru O, Boutet P, Fernández-Messina L, Agüera-González S, Skepper JN, Valés-Gómez M, Reyburn HT. Natural killer cell cytotoxicity is suppressed by exposure to the human NKG2D ligand MICA* 008 that is shed by tumor cells in exosomes. Can Res. 2010;70:481-9.

83. Hedlund M, Nagaeva O, Kargl D, Baranov V, Mincheva-Nilsson L. Thermal-and oxidative stress causes enhanced release of NKG2D ligand-bearing immunosuppressive exosomes in leukemia/lymphoma T and B cells. PloS one. 2011;6:e16899.

84. Labani-Motlagh A, Israelsson P, Ottander U, Lundin E, Nagaev I, Nagaeva $\mathrm{O}$, Dehlin E, Baranov V, Mincheva-Nilsson L. Differential expression of ligands for NKG2D and DNAM-1 receptors by epithelial ovarian cancerderived exosomes and its influence on NK cell cytotoxicity. Tumor Biology. 2016;37:5455-66.

85. Szczepanski MJ, Szajnik M, Welsh A, Whiteside TL, Boyiadzis M. Blast-derived microvesicles in sera from patients with acute myeloid leukemia suppress natural killer cell function via membrane-associated transforming growth factor- $\beta 1$. Haematologica. 2011;96:1302.

86. Ferguson Bennit HR, Gonda A, Kabagwira J, Oppegard L, Chi D, Licero Campbell J, De Leon M, Wall NR. Natural Killer Cell Phenotype and Functionality Affected by Exposure to Extracellular Survivin and LymphomaDerived Exosomes. Int J Mol Sci. 2021;22:1255.

87. Lemke D, Pfenning P-N, Sahm F, Klein A-C, Kempf T, Warnken U, Schnölzer M, Tudoran R, Weller M, Platten M. Costimulatory protein $4 \mathrm{lgB} 7 \mathrm{H} 3$ drives the malignant phenotype of glioblastoma by mediating immune escape and invasiveness. Clin Cancer Res. 2012;18:105-17.

88. Sharma P, Diergaarde B, Ferrone S, Kirkwood JM, Whiteside TL. Melanoma cell-derived exosomes in plasma of melanoma patients suppress functions of immune effector cells. Sci Rep. 2020:10:1-11.

89. Nakano $T$, Chen IH, Wang CC, Chen PJ, Tseng HP, Huang KT, Hu TH, Li LC, Goto S, Cheng YF. Circulating exosomal miR-92b: Its role for cancer immunoediting and clinical value for prediction of posttransplant hepatocellular carcinoma recurrence. Am J Transplant. 2019;19:3250-62.

90. Zhang P-F, Gao C, Huang X-Y, Lu J-C, Guo X-J, Shi G-M, Cai J-B, Ke A-W. Cancer cell-derived exosomal circUHRF1 induces natural killer cell exhaustion and may cause resistance to anti-PD1 therapy in hepatocellular carcinoma. Mol Cancer. 2020;19:1-15.

91. Huang Y, Luo Y, Ou W, Wang Y, Dong D, Peng X, Luo YJCci. Exosomal IncRNA SNHG10 derived from colorectal cancer cells suppresses natural killer cell cytotoxicity by upregulating INHBC. Cancer cell international. 2021:21:1-16. 
92. Waldhauer I, Steinle A. NK cells and cancer immunosurveillance. Oncogene. 2008;27:5932-43.

93. Duan S, Guo W, Xu Z, He Y, Liang C, Mo Y, Wang Y, Xiong F, Guo C, Li $Y$. Natural killer group 2D receptor and its ligands in cancer immune escape. Mol Cancer. 2019;18:1-14.

94. López-Soto A, Huergo-Zapico L, Acebes-Huerta A, Villa-Alvarez M, Gonzalez S. NKG2D signaling in cancer immunosurveillance. Int J Cancer. 2015;136:1741-50.

95. Saito H, Osaki T, Ikeguchi M. Decreased NKG2D expression on NK cells correlates with impaired NK cell function in patients with gastric cancer. Gastric Cancer. 2012;15:27-33.

96. Xing S, de Ferrari Andrade L. NKG2D and MICA/B shedding: a'tag game'between NK cells and malignant cells. Clinical \& Translational Immunology. 2020;9:e1230.

97. de Andrade LF, Kumar S, Luoma AM, Ito Y, da Silva PHA, Pan D, Pyrdol JW, Yoon $\mathrm{CH}$, Wucherpfennig KW. Inhibition of MICA and MICB shedding elicits NK-Cell-mediated immunity against tumors resistant to cytotoxic T Cells. Cancer Immunol Res. 2020;8:769-80.

98. Moloudizargari M, Asghari MH, Mortaz E. Inhibiting exosomal MIC-A and MIC-B shedding of cancer cells to overcome immune escape: new insight of approved drugs. DARU Journal of Pharmaceutical Sciences. 2019;27:879-84

99. Chen W, Jiang J, Xia W, Huang J. Tumor-related exosomes contribute to tumor-promoting microenvironment: an immunological perspective. Journal of Immunology Research. 2017;2017:1073947.

100. Clayton A, Tabi Z. Exosomes and the MICA-NKG2D system in cancer. Blood Cells Mol Dis. 2005:34:206-13.

101. Gonzalez-Rodriguez AP, Villa-Álvarez M, Sordo-Bahamonde C, LorenzoHerrero S, Gonzalez S. NK cells in the treatment of hematological malignancies. J Clin Med. 2019;8:1557.

102. Fernández-Messina L, Ashiru $O$, Boutet $P$, Agüera-González S, Skepper JN, Reyburn HT, Valés-Gómez MJJoBC. Differential mechanisms of shedding of the glycosylphosphatidylinositol (GPI)-anchored NKG2D ligands. J Biol Chem. 2010;285:8543-51.

103. Tai YL, Chen KC, Hsieh JT, Shen TL. Exosomes in cancer development and clinical applications. Cancer Sci. 2018;109:2364-74

104. Kok VC, Yu C-C. Cancer-derived exosomes: Their role in cancer biology and biomarker development. Int J Nanomed. 2020;15:8019.

105. Ashiru O, López-Cobo S, Fernández-Messina L, Pontes-Quero S, Pandolfi R, Reyburn HT, Valés-Gómez M. A GPI anchor explains the unique biological features of the common NKG2D-ligand allele MICA* 008 . Biochemical Journal. 2013;454:295-302.

106. López-Cobo S, Pieper N, Campos-Silva C, García-Cuesta EM, Reyburn HT, Paschen A, Valés-Gómez M. Impaired NK cell recognition of vemurafenib-treated melanoma cells is overcome by simultaneous application of histone deacetylase inhibitors. Oncoimmunology. 2018;7:e1392426

107. Liu M, Kuo F, Capistrano KJ, Kang D, Nixon BG, Shi W, Chou C, Do MH, Stamatiades EG, Gao S. TGF- $\beta$ suppresses type 2 immunity to cancer. Nature. 2020;587:115-20.

108. Gorelik L, Flavell RA. Transforming growth factor- $\beta$ in T-cell biology. Nat Rev Immunol. 2002:2:46-53.

109. Jin K, Zhou F, Zhang L. Cancer Environment Immunotherapy: targeting TGF- $\beta$ finds its way towards tissue healing and vasculature remodeling. Signal Transduct Target Ther. 2021;6:1-2.

110. Visan I. Targeting TGF- $\beta$ in cancer. Nat Immunol. 2018;19:316-316.

111. Ghahremanifard P, Chanda A, Bonni S, Bose P. TGF- $\beta$ Mediated Immune Evasion in Cancer-Spotlight on Cancer-Associated Fibroblasts. Cancers. 2020;12:3650.

112. Lazarova M, Steinle A. Impairment of NKG2D-mediated tumor immunity by TGF- $\beta$. Front Immunol. 2019;10:2689.

113. Rouce RH, Shaim H, Sekine T, Weber G, Ballard B, Ku S, Barese C, Murali V, Wu M-F, Liu H. The TGF-B/SMAD pathway is an important mechanism for NK cell immune evasion in childhood B-acute lymphoblastic leukemia. Leukemia. 2016:30:800-11.

114. Slattery K, Gardiner CM. NK cell metabolism and TGF $\beta$-implications for immunotherapy. Front Immunol. 2019;10:2915.

115. Lee J-C, Lee K-M, Kim D-W, Heo DSJTJol. Elevated TGF- $\beta 1$ secretion and down-modulation of NKG2D underlies impaired NK cytotoxicity in cancer patients. J Immunol. 2004;172:7335-40.
116. Boyiadzis M, Hong C-S, Whiteside TL. Biologically-active exosomes in plasma of AML patients inhibit innate immunity and promote leukemia progression. J Immunother Cancer. 2015;3:1-1.

117. Sood R, Talwar-Trikha A, Chakrabarti S, Nucifora GJL. MDS1/EVI1 enhances TGF- $\beta 1$ signaling and strengthens its growth-inhibitory effect, but the leukemia-associated fusion protein AML1/MDS1/EVI1, product of the $t(3 ; 21)$, abrogates growth-inhibition in response to TGFB1. Leukemia. 1999;13:348-57.

118. Li A, Zhang T, Zheng M, Liu Y, Chen Z. Exosomal proteins as potential markers of tumor diagnosis. J Hematol Oncol. 2017;10:1-9.

119. Vigano S, Alatzoglou D, Irving M, Ménétrier-Caux C, Caux C, Romero P, Coukos $\mathrm{G}$. Targeting adenosine in cancer immunotherapy to enhance T-cell function. Front Immunol. 2019;10:925.

120. Boison D, Yegutkin GG. Adenosine metabolism: emerging concepts for cancer therapy. Cancer Cell. 2019;36:582-96.

121. Neo SY, Yang Y, Record J, Ma R, Chen X, Chen Z, Tobin NP, Blake E, Seitz C, Thomas R. CD73 immune checkpoint defines regulatory NK cells within the tumor microenvironment. J Clin Investig. 2020;130:1185-98.

122. Leone RD, Emens $L A$. Targeting adenosine for cancer immunotherapy. J Immunother Cancer. 2018:6:1-9.

123. Vijayan D, Young A, Teng MW, Smyth MJ. Targeting immunosuppressive adenosine in cancer. Nat Rev Cancer. 2017:17:709-24.

124. Allard B, Allard D, Buisseret L, Stagg J. The adenosine pathway in immuno-oncology. Nat Rev Clin Oncol. 2020;17:611-29.

125. Schuler P, Saze Z, Hong CS, Muller L, Gillespie D, Cheng D, Harasymczuk M, Mandapathil M, Lang S, Jackson E. Human CD 4+ CD 39+ regulatory $T$ cells produce adenosine upon co-expression of surface CD 73 or contact with CD 73+ exosomes or CD 73+ cells. Clin Exp Immunol. 2014;177:531-43.

126. Young A, Ngiow SF, Gao Y, Patch A-M, Barkauskas DS, Messaoudene M, Lin G, Coudert JD, Stannard KA, Zitvogel L. A2AR adenosine signaling suppresses natural killer cell maturation in the tumor microenvironment. Can Res. 2018;78:1003-16.

127. Terrén I, Orrantia A, Vitallé J, Zenarruzabeitia O, Borrego F. NK cell metabolism and tumor microenvironment. Front Immunol. 2019;10:2278.

128. O'Brien KL, Finlay DK. Immunometabolism and natural killer cell responses. Nat Rev Immunol. 2019;19:282-90.

129. Wu M, Wang G, Hu W, Yao Y, Yu X-F. Emerging roles and therapeutic value of exosomes in cancer metastasis. Mol Cancer. 2019;18:1-11.

130. Andreola G, Rivoltini L, Castelli C, Huber V, Perego P, Deho P, Squarcina P, Accornero P, Lozupone F, Lugini L. Induction of lymphocyte apoptosis by tumor cell secretion of FasL-bearing microvesicles. J Exp Med. 2002;195:1303-16.

131. Abusamra AJ, Zhong Z, Zheng X, Li M, Ichim TE, Chin JL, Min W-P. Tumor exosomes expressing Fas ligand mediate CD8+ T-cell apoptosis. Blood Cells Mol Dis. 2005;35:169-73.

132. Huber V, Fais $S$, lero M, Lugini L, Canese P, Squarcina P, Zaccheddu A, Colone M, Arancia G, Gentile M. Human colorectal cancer cells induce T-cell death through release of proapoptotic microvesicles: role in immune escape. Gastroenterology. 2005;128:1796-804

133. Bergmann C, Strauss L, Wieckowski E, Czystowska M, Albers A, Wang Y, Zeidler R, Lang S, Whiteside TL. Tumor-derived microvesicles in sera of patients with head and neck cancer and their role in tumor progression. Head Neck. 2009;31:371-80.

134. Wieckowski EU, Visus C, Szajnik M, Szczepanski MJ, Storkus WJ, Whiteside TL. Tumor-derived microvesicles promote regulatory $T$ cell expansion and induce apoptosis in tumor-reactive activated CD8 $+\mathrm{T}$ lymphocytes. J Immunol. 2009;183:3720-30.

135. Martınez-Lorenzo MJ, Anel A, Alava MA, Piñeiro A, Naval J, Lasierra P, Larrad $L$. The human melanoma cell line MelJuSo secretes bioactive Fas $L$ and APO2L/TRAIL on the surface of microvesicles. Possible contribution to tumor counterattack. Experimental cell research. 2004;295:315-29.

136. Yang S, Wei W, Zhao Q. B7-H3, a checkpoint molecule, as a target for cancer immunotherapy. Int J Biol Sci. 2020;16:1767.

137. Lee Y-h. Martin-Orozco N, Zheng P, Li J, Zhang P, Tan H, Park HJ, Jeong M, Chang SH, Kim B-S: Inhibition of the B7-H3 immune checkpoint limits tumor growth by enhancing cytotoxic lymphocyte function. Cell Res. 2017;27:1034-45.

138. Picarda E, Ohaegbulam KC, Zang X. Molecular pathways: targeting B7-H3 (CD276) for human cancer immunotherapy. Clin Cancer Res. 2016:22:3425-31. 
139. Chen G, Huang AC, Zhang W, Zhang G, Wu M, Xu W, Yu Z, Yang J, Wang B, Sun H, et al. Exosomal PD-L1 contributes to immunosuppression and is associated with anti-PD-1 response. Nature. 2018;560:382-6.

140. Tang Y, Zhang P, Wang Y, Wang J, Su M, Wang Y, Zhou L, Zhou J, Xiong W, Zeng Z. The Biogenesis, Biology, and Clinical Significance of Exosomal PD-L1 in Cancer. Front Immunol. 2020;11:604.

141. Yang Y, Li C-W, Chan L-C, Wei Y, Hsu J-M, Xia W, Cha J-H, Hou J, Hsu JL, Sun L. Exosomal PD-L1 harbors active defense function to suppress $T$ cell killing of breast cancer cells and promote tumor growth. Cell Res. 2018;28:862-4.

142. Shimada Y, Matsubayashi J, Kudo Y, Maehara S, Takeuchi S, Hagiwara M, Kakihana M, Ohira T, Nagao T, Ikeda N. Serum-derived exosomal PD-L1 expression to predict anti-PD-1 response and in patients with nonsmall cell lung cancer. Sci Rep. 2021;11:1-10.

143. Quatrini L, Mariotti FR, Munari E, Tumino N, Vacca P, Moretta L. The immune checkpoint PD-1 in natural killer cells: expression, function and targeting in tumour immunotherapy. Cancers. 2020;12:3285.

144. Sun Z, Shi K, Yang S, Liu J, Zhou Q, Wang G, Song J, Li Z, Zhang Z, Yuan W. Effect of exosomal miRNA on cancer biology and clinical applications. Mol Cancer. 2018:17:1-19.

145. Yousefi H, Maheronnaghsh M, Molaei F, Mashouri L, Aref AR, Momeny M, Alahari SK. Long noncoding RNAs and exosomal IncRNAs: classification, and mechanisms in breast cancer metastasis and drug resistance. Oncogene. 2020;39:953-74.

146. Pathania AS, Challagundla KB. Exosomal long non-coding RNAs: Emerging players in the tumor microenvironment. Molecular Therapy-Nucleic Acids. 2020:23:1371-83.

147. Han S, Qi Y, Luo Y, Chen X, Liang H. Exosomal Long Non-Coding RNA: Interaction Between Cancer Cells and Non-Cancer Cells. Frontiers in Oncology. 2020;10:617837.

148. Xu J, Niu T. Natural killer cell-based immunotherapy for acute myeloid leukemia. J Hematol Oncol. 2020;13:1-20.

149. Carlsten M, Järås M. Natural killer cells in myeloid malignancies: immune surveillance, NK cell dysfunction, and pharmacological opportunities to bolster the endogenous NK cells. Front Immunol. 2019;10:2357

150. Minetto P, Guolo F, Pesce S, Greppi M, Obino V, Ferretti E, Sivori S, Genova C, Lemoli RM, Marcenaro E. Harnessing NK cells for cancer treatment. Front Immunol. 2019;10:2836.

151. Miller JS, Lanier LL. Natural killer cells in cancer immunotherapy. Annual review of cancer biology. 2019;3:77-103.

152. Nigro CL, Macagno M, Sangiolo D, Bertolaccini L, Aglietta M, Merlano MC. NK-mediated antibody-dependent cell-mediated cytotoxicity in solid tumors: biological evidence and clinical perspectives. Annals of translational medicine. 2019;7:105.

153. Wang W, Erbe AK, Hank JA, Morris ZS, Sondel PM. NK cell-mediated antibody-dependent cellular cytotoxicity in cancer immunotherapy. Front Immunol. 2015;6:368.

154. Seidel UJE, Schlegel P, Lang P. Natural killer cell mediated antibodydependent cellular cytotoxicity in tumor immunotherapy with therapeutic antibodies. Front Immunol. 2013;4:76.

155. Battke C, Ruiss R, Welsch U, Wimberger P, Lang S, Jochum S, Zeidler R. Tumour exosomes inhibit binding of tumour-reactive antibodies to tumour cells and reduce ADCC. Cancer Immunol Immunother. 2011;60:639-48

156. Marleau AM, Chen C-S, Joyce JA, Tullis RH. Exosome removal as a therapeutic adjuvant in cancer. J TransI Med. 2012;10:1-12.

157. Datta A, Kim H, McGee L, Johnson AE, Talwar S, Marugan J, Southall N, Hu X, Lal M, Mondal D. High-throughput screening identified selective inhibitors of exosome biogenesis and secretion: A drug repurposing strategy for advanced cancer. Sci Rep. 2018;8:1-13.

158. Catalano M, O'Driscoll L. Inhibiting extracellular vesicles formation and release: a review of EV inhibitors. Journal of extracellular vesicles. 2020:9:1703244.

159. Ciravolo V, Huber V, Ghedini GC, Venturelli E, Bianchi F, Campiglio M, Morelli D, Villa A, Mina PD, Menard S. Potential role of HER2-overexpressing exosomes in countering trastuzumab-based therapy. J Cell Physiol. 2012;227:658-67.

160. Dong X, Bai X, Ni J, Zhang H, Duan W, Graham P, Li Y. Exosomes and breast cancer drug resistance. Cell Death Dis. 2020;11:1-14.
161. Waldmann TA, Dubois S, Miljkovic MD, Conlon KC. IL-15 in the Combination Immunotherapy of Cancer. Front Immunol. 2020;1 1:868.

162. Otegbeye F, Ojo E, Moreton S, Mackowski N, Lee DA, de Lima M, Wald DN. Inhibiting TGF-beta signaling preserves the function of highly activated, in vitro expanded natural killer cells in AML and colon cancer models. PloS one. 2018;13:e0191358.

163. Alvarez M, Bouchlaka MN, Sckisel GD, Sungur CM, Chen M, Murphy WJ. Increased antitumor effects using IL-2 with anti-TGF- $\beta$ reveals competition between mouse NK and CD8 T cells. J Immunol. 2014:193:1709-16.

164. Alvarez M, Dunai C, Khuat LT, Aguilar EG, Barao I, Murphy WJ. IL-2 and Anti-TGF- $\beta$ Promote NK Cell Reconstitution and Anti-tumor Effects after Syngeneic Hematopoietic Stem Cell Transplantation. Cancers. 2020;12:3189

165. Yang Y, Xiu F, Cai Z, Wang J, Wang Q, Fu Y, Cao XJJocr. Increased induction of antitumor response by exosomes derived from interleukin-2 gene-modified tumor cells. Journal of cancer research and clinical oncology. 2007;133:389-99.

166. Lewis ND, Sia CL, Kirwin K, Haupt S, Mahimkar G, Zi T, Xu K, Dooley K, Jang SC, Choi BJMCT. Exosome Surface Display of IL12 Results in Tumor-Retained Pharmacology with Superior Potency and Limited Systemic Exposure Compared with Recombinant IL12. Mol Cancer Ther. 2021;20:523-34.

167. Xiu F, Cai Z, Yang Y, Wang X, Wang J. Cao XJJomm: Surface anchorage of superantigen SEA promotes induction of specific antitumor immune response by tumor-derived exosomes. J Mol Med (Berl). 2007:85:511-21

168. Xiao W, Dong W, Zhang C, Saren G, Geng P, Zhao H, Li Q, Zhu J, Li G, Zhang SJEJoMR. Effects of the epigenetic drug MS-275 on the release and function of exosome-related immune molecules in hepatocellular carcinoma cells. Eur J Med Res. 2013;18:1-7.

169. Lv L-H, Wan Y-L, Lin Y, Zhang W, Yang M, Li G-L, Lin H-M, Shang C-Z, Chen Y-J, Min JJJoBC. Anticancer drugs cause release of exosomes with heat shock proteins from human hepatocellular carcinoma cells that elicit effective natural killer cell antitumor responses in vitro. J Biol Chem. 2012;287:15874-85.

170. Zhu M-C, Xiong P, Li G-L, Zhu M. Could lung cancer exosomes induce apoptosis of natural killer cells through the p75NTR-proNGF-sortilin axis? Med Hypotheses. 2017;108:151-3.

171. Espinoza JL, Takami A, Yoshioka K, Nakata K, Sato T, Kasahara Y, Nakao S. Human microRNA-1245 down-regulates the NKG2D receptor in natural killer cells and impairs NKG2D-mediated functions. Haematologica. 2012;97:1295

172. Cao Y, Wang X, Jin T, Tian Y, Dai C, Widarma C, Song R, Xu F. Immune checkpoint molecules in natural killer cells as potential targets for cancer immunotherapy. Signal Transduct Target Ther. 2020;5:1-19.

\section{Publisher's Note}

Springer Nature remains neutral with regard to jurisdictional claims in published maps and institutional affiliations.

Ready to submit your research? Choose BMC and benefit from:

- fast, convenient online submission

- thorough peer review by experienced researchers in your field

- rapid publication on acceptance

- support for research data, including large and complex data types

- gold Open Access which fosters wider collaboration and increased citations

- maximum visibility for your research: over $100 \mathrm{M}$ website views per year

At BMC, research is always in progress.

Learn more biomedcentral.com/submissions 